\title{
Genomics of medulloblastoma: from Giemsa-banding to next-generation sequencing in 20 years
}

\author{
Paul A. Northcott, M.Sc., ${ }^{1-3}$ James T. Rutka, M.D., Ph.D., ${ }^{1,3}$ \\ and Michael D. TaYlor, M.D., Ph.D. ${ }^{1-3}$ \\ ${ }^{1}$ Division of Neurosurgery, Arthur and Sonia Labatt Brain Tumour Research Centre; \\ ${ }^{2}$ Program in Developmental and Stem Cell Biology, The Hospital for Sick Children; \\ and ${ }^{3}$ Department of Laboratory Medicine and Pathobiology, University of Toronto, Ontario, Canada
}

\begin{abstract}
Advances in the field of genomics have recently enabled the unprecedented characterization of the cancer genome, providing novel insight into the molecular mechanisms underlying malignancies in humans. The application of high-resolution microarray platforms to the study of medulloblastoma has revealed new oncogenes and tumor suppressors and has implicated changes in DNA copy number, gene expression, and methylation state in its etiology. Additionally, the integration of medulloblastoma genomics with patient clinical data has confirmed molecular markers of prognostic significance and highlighted the potential utility of molecular disease stratification. The advent of next-generation sequencing technologies promises to greatly transform our understanding of medulloblastoma pathogenesis in the next few years, permitting comprehensive analyses of all aspects of the genome and increasing the likelihood that genomic medicine will become part of the routine diagnosis and treatment of medulloblastoma. (DOI: 10.3171/2009.10.FOCUS09218)
\end{abstract}

KeY Words $\bullet$ medulloblastoma $\bullet$ genomics $\bullet$ microarrays
next-generation sequencing

$\mathrm{G}$ ENOMICS involves the study of genes and their function, typically in the context of an organism, a tissue, or a particular cell type. Cancer is a genomic disease that accounted for an estimated $\sim 640,000$ deaths in the US and Canada in 2008. ${ }^{73,97}$ The goal of cancer genomics is to develop a comprehensive inventory of the full spectrum of mutations, whether inherited or acquired, that contribute to tumorigenesis. Ultimately, through a better understanding of the cancer genome, targeted treatment options can be developed and implemented so that deaths due to cancer can be reduced in the future.

The human genome consists of $\sim 3$ billion base pairs of DNA and encodes an estimated 24-25,000 unique protein-coding genes. ${ }^{71,133}$ During tumorigenesis, a vari-

Abbreviations used in this paper: $\mathrm{aCGH}=$ array comparative genomic hybridization; CGNP = cerebellar granule neuron precursor; FISH = fluorescence in situ hybridization; G-banding = Giemsa banding; MAPK = mitogen-activated protein kinase; miRNA = microRNA; NGS = next-generation sequencing; PDGFR = platelet-derived growth factor receptor; RT-PCR = reverse transcriptase-polymerase chain reaction; SAGE $=$ serial analysis of gene expression; $\mathrm{SHH}=$ sonic hedgehog; siRNA = short interfering RNA; SKY = spectral karyotyping; SNP = singlenucleotide polymorphism; sPNET = supratentorial primitive neuroectodermal tumor; TCGA $=$ The Cancer Genome Atlas; TMA = tissue microarray; 5-aza $=5$-aza-2'-deoxycytidine. ety of somatic mutations arise at the level of the genome, collectively providing a selective growth advantage to cells harboring these mutations and promoting the onset of cancer. Some examples of the somatic mutations in the cancer genome include single base pair substitutions, insertions and deletions of DNA segments, structural rearrangements such as duplications, inversions, and translocations, as well as gene amplifications and deletions. ${ }^{149}$ Estimates from recent genome-wide sequencing efforts have suggested that a given cancer may contain anywhere from 40 to over 100 somatic mutations. ${ }^{78,125,173}$ Since these numbers do not directly account for genes affected by structural changes and copy number aberrations, the actual number of genes targeted for mutation in a given tumor is probably even higher. Beyond the genome, deregulation of the epigenome, including hypermethylation of gene promoters and changes to the histone code, also contributes to cellular transformation. ${ }^{23,75,76,156}$ Collectively, these abnormal genomic and epigenomic states in a cancer cell aberrantly impact gene expression, leading to the disruption of normal cellular processes, including cell division. Comprehensive cancer genomics, therefore, include studies at the level of the genome, epigenome, and transcriptome.

Medulloblastoma is an embryonal tumor of the cerebellum and the most common malignant brain tumor 
in childhood. ${ }^{53,101}$ Although 5-year overall survival rates have reached $60-80 \%$, survivors often face a variety of long-term neurological, neuroendocrine, and social sequelae as a result of conventional treatment regimens (surgery, radiotherapy, and chemotherapy). ${ }^{40,46}$ It is therefore imperative for us to gain a better understanding of the genes driving medulloblastoma oncogenesis so that future targeted therapies that are more effective and less toxic can be made available.

Much of our current understanding of the molecular basis of medulloblastoma has been derived from insights into hereditary tumor syndromes ${ }^{151}$ and candidate gene approaches focused on developmental signaling pathways. ${ }^{60,96,170}$ For instance, individuals with Gorlin or Turcot syndrome possess germline mutations in the PTCHI and APC tumor suppressor genes, respectively, and are predisposed to medulloblastoma, among other cancers. ${ }^{6,51,62,63}$ Studies of the PTCH1 gene in Gorlin syndrome and sporadic medulloblastomas, as well as knockout studies of its mouse homolog, Ptc, have helped to establish a role for aberrant $\mathrm{SHH}$ signaling in $\sim 25-35 \%$ of medulloblastomas..$^{55,96}$ Similarly, the identification of $A P C$ mutations in Turcot syndrome and more frequent mutations of CTNNB1 in sporadic cases have implicated the Wnt signaling cascade in $~ 10-15 \%$ of patients with medulloblastomas. ${ }^{55,96}$ Furthermore, patients with LiFraumeni syndrome have germline TP53 mutations and can have a broad spectrum of cancer types, including medulloblastoma. ${ }^{95,148}$

Aside from what has been learned from the study of these familial tumor syndromes, the majority of additional oncogenes and tumor suppressor genes implicated in medulloblastoma have been discovered from a priori candidate gene selection. Mutational screening has further implicated additional SHH (SUFU and SMO) and Wnt (AXIN1) pathway genes. ${ }^{55,96}$ In addition, the Notch pathway is deregulated in a subset of human medulloblastomas and activated in certain mouse models. ${ }^{55,96}$ Furthermore, candidate epigenetic approaches have revealed hypermethylation of the promoter regions of known tumor suppressor genes: HICl, RASSF1A, CASP8, and others. ${ }^{90}$ The relevance of several of these genes has been further validated in mouse models of medulloblastoma. ${ }^{50,129,134}$ Although these single-gene and/or candidate-gene studies have shed significant light on our understanding of medulloblastoma pathogenesis, the candidates identified to date very likely represent only a small piece of the genomic puzzle responsible for the onset and progression of this pediatric tumor. Indeed, recent data from wholegenome sequencing projects of multiple tumor types implicate as many as 100 mutated genes per genome. ${ }^{78,125,173}$ If such estimates prove applicable to the medulloblastoma genome, many candidates have yet to be identified.

The goal of this review was to detail the progress that has been made in our understanding of the medulloblastoma genome over the last 20+ years, with specific emphasis on global, unbiased genomic profiling. Although what has been learned from gene- and pathway-specific studies of medulloblastoma has been indispensable to our knowledge of this disease, these findings will not be discussed in detail here but have been reviewed elsewhere. ${ }^{55,96}$ The summary presented here describes how the technologies available to study the medulloblastoma genome have evolved over the last 2 decades (Fig. 1) and shows how much of the progress in this field has been dictated by both the size of the sample cohorts analyzed and the resolution of the technologies used in their study. A glimpse into what is to come in the near future of medulloblastoma genomics will also be discussed.

\section{Early Cytogenetics and Karyotyping of Medulloblastoma}

It has been over 20 years since G-banding was first used to disclose chromosomal abnormalities in medulloblastoma. It is a classic staining technique used to visualize a cell's karyotype, producing an alternating pattern of dark (heterochromatin) and light (euchromatin) bands along metaphase chromosomes..11147 Early studies conducted at Duke University Medical Center and The Children's Hospital of Philadelphia provided original and informative descriptions of the medulloblastoma karyotype. ${ }^{17,19,59}$ Of significant interest, both of these groups reported an isochromosome of the long arm of chromosome $17[\mathrm{i}(17 \mathrm{q})]$ as the most frequent structural abnormality and, in at least a few cases, the only aberration observed. Isochromosome $17 \mathrm{q}$ is the most common isochromosome in human cancer, ${ }^{105}$ generating a net loss of 1 copy of the majority of $17 \mathrm{p}$ and a net gain of 1 copy of 17q (Fig. 2A). Frequent loss of heterozygosity on chromosome $17 \mathrm{p}$ in medulloblastoma was independently confirmed by multiple groups in the early 1990s, typically through deletion mapping by restriction fragment length polymorphism (RFLP) analysis. ${ }^{29,30,72,135,153}$ At present, cytogenetic aberrations affecting chromosome 17 remain the most common structural changes noted in medulloblastoma (Table 1): ${ }^{119,126,138}$ however, insight into the individual gene or combination of genes on this chromosome that drive tumorigenesis has not significantly improved since these early findings.

The establishment and cytogenetic characterization of permanent medulloblastoma cell lines and xenografts in the late 80 s and early 90 s also provided initial insight into the prevalence of oncogene amplification in medulloblastoma. Amplification of the MYC locus on 8q24, often in the form of double minutes, was reported in multiple cell lines and confirmed in primary tumors by several groups. ${ }^{8,18,48,130,157}$ The $M Y C$ family of protooncogenes (MYC, MYCN, and MYCL1) remain among the most prevalent targets of gene amplification in medulloblastoma (Fig. 2B). ${ }^{119,126}$

The application of $\mathrm{CGH}$ to the cytogenetic characterization of medulloblastoma in the late 90 s resulted in a much greater appreciation of the degree of genomic imbalance present in this cancer. Using $\mathrm{CGH}$ to profile a panel of 27 primary medulloblastomas, Reardon and colleagues ${ }^{136}$ described frequent losses on chromosomes $10 \mathrm{q}, 11,16 \mathrm{q}, 17 \mathrm{p}$, and $8 \mathrm{p}$ as well as recurrent gains on chromosomes 7 and 17q. Several complementary followup studies based on a combination of G-banding, CGH, SKY, and FISH confirmed these now well-recognized regions of genomic instability in medulloblastoma and 


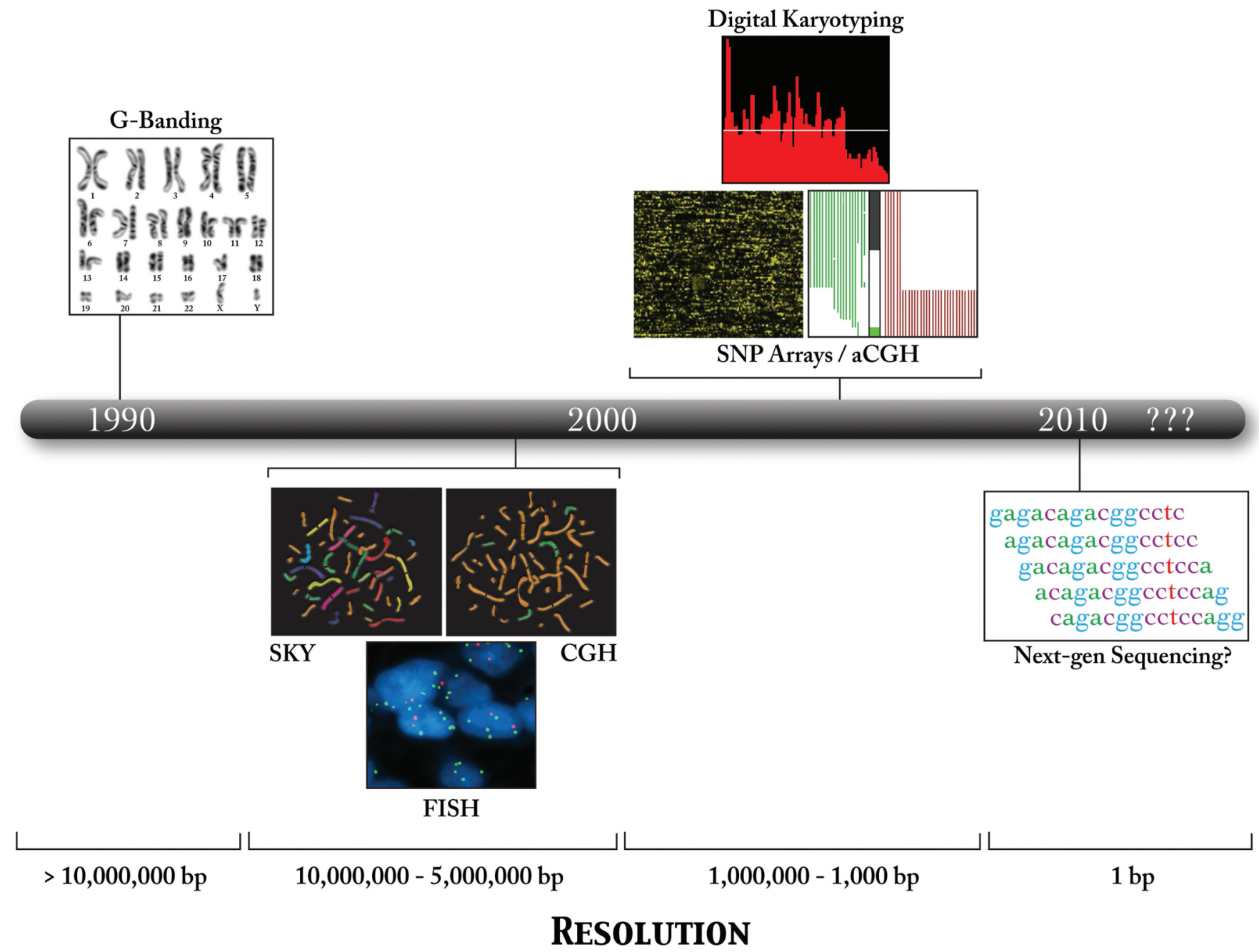

FIG. 1. Timeline showing the evolution of genomic technologies over the last 2 decades and their application to the study of medulloblastoma. Dates reflect the application of referenced technologies to studies of the medulloblastoma genome. Listed below each time period is the approximate resolution $(\mathrm{bp})$ of the techniques shown.

shed light on additional candidate regions. ${ }^{2,7,12,20,32,38,56,117}$ An innovative study involving members of our group retrospectively documented a series of 19 primary medulloblastomas (in addition to 5 sPNETs) using classic Gbanding, FISH, CGH, and SKY. ${ }^{12}$ Spectral karyotyping is a multicolored FISH procedure that permits the identification of structural rearrangements and origins of marker chromosomes in the genome in a single experiment. ${ }^{13}$ This "chromosome painting" technique is particularly useful for detecting structural aberrations lacking a net change in copy number, such as balanced translocations. The use of SKY in this study enabled the comprehensive identification of recurrent structural rearrangements in medulloblastoma, including those on chromosomes 7,17 , $3,14,10$, and 22 -something not possible through the use of G-banding or $\mathrm{CGH}$ alone.

Although these cumulative efforts provided the pediatric brain tumor community with relatively detailed summaries of the medulloblastoma karyotype, not until the advent of new technologies capable of detecting copy number changes at a much higher resolution could novel candidate oncogenes and tumor suppressors in medulloblastoma be more efficiently identified through the use of genomics. Over the past 5 years, novel, high-resolution (that is, submegabase) genomic technologies have become available. ${ }^{34,112,147}$ The applications of some of these technologies in studies of the medulloblastoma genome are discussed in detail below.

\section{High-Resolution Analysis of Medulloblastoma: Digital Karyotyping, aCGH, and SNP Genotyping Arrays}

High-resolution genomic profiling of medulloblastoma has recently implicated multiple candidate oncogenes that are recurrently amplified in this malignancy (Table 2). In 2005, 2 very similar but independent studies led by Greg Riggins ${ }^{21}$ and Hai Yan ${ }^{35}$ used digital karyotyping to identify novel regions of copy number aberrations in the medulloblastoma genome. Digital karyotyping uses short sequence tags derived from specific genomic loci to provide a quantitative and relatively high-resolution profile 
P. A. Northcott, J. T. Rutka, and M. D. Taylor

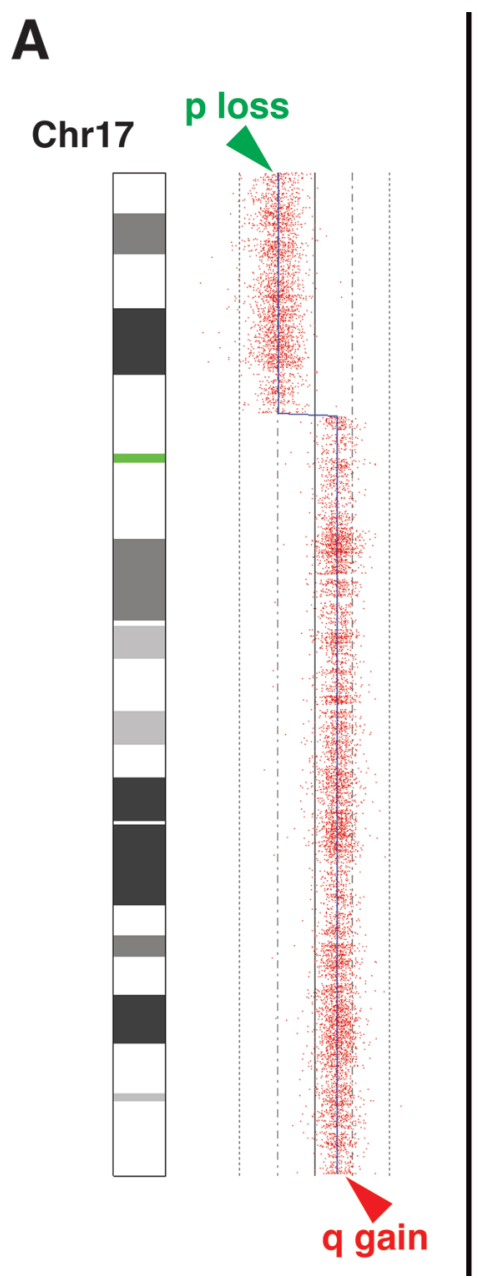

B
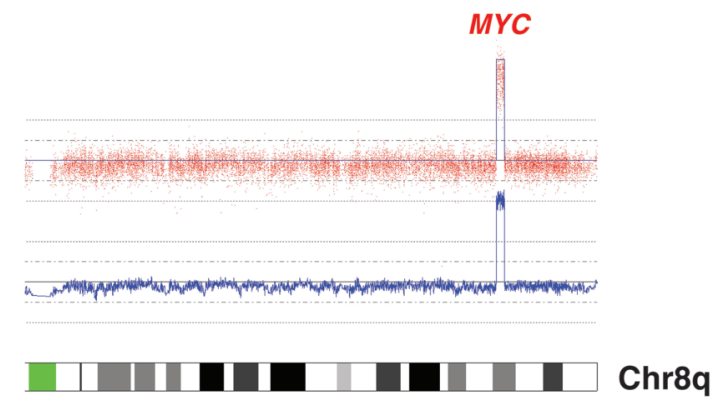

\section{MYCN}
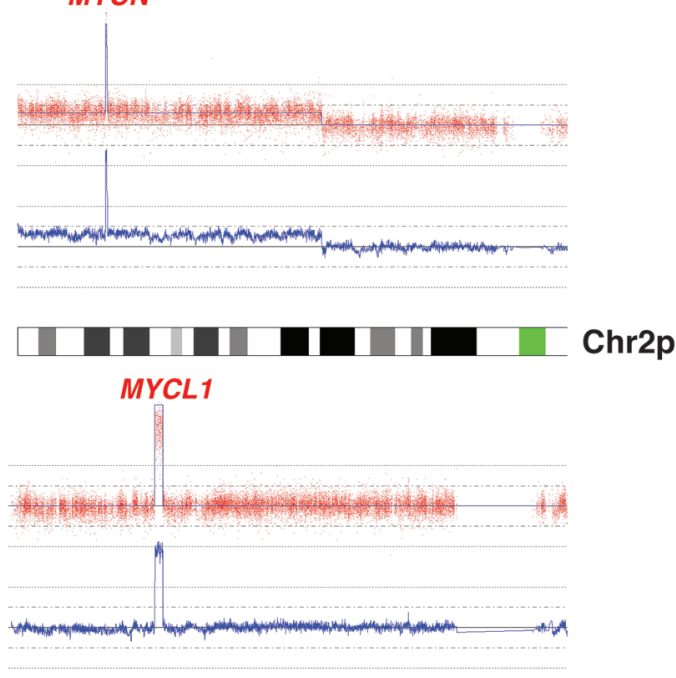

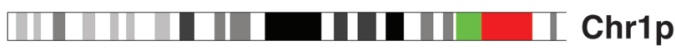

Fig. 2. Prominent genomic aberrations in medulloblastoma. A: Isochromosome 17q in medulloblastoma. Single-nucleotide polymorphism array copy number profile for a medulloblastoma patient with a characteristic $\mathrm{i}(17 \mathrm{q})$ abnormality. Isochromosome $17 q$ is the most common cytogenetic aberration in medulloblastoma, identified in $\sim 30-40 \%$ of cases. This structural abnormality results in a net loss of 1 copy of chromosome 17p and a net gain in 1 copy of 17q. Chromosome 17p loss and q gain are indicated in the copy number plot with green and red arrowheads, respectively. B: The MYC family amplification in medulloblastoma. Single-nucleotide polymorphism array copy number output showing focal, high-level amplification of MYC (8q24, upper portion of B), MYCN (2p24, middle portion of B), and MYCL1 (1p34, lower portion of B) in primary medulloblastomas. The MYC family protooncogenes are collectively targeted for amplification in $\sim 10 \%$ of primary medulloblastoma cases, more frequently than any other known oncogenes.

of copy number aberrations throughout the genome. ${ }^{87,168}$ Boon et al. ${ }^{21}$ karyotyped 5 medulloblastoma cell lines by sequencing $\sim 200,000$ genomic tags per genome, identifying amplification of the OTX2 homeobox gene on chromosome 14q22 in the D487Med cell line. Using quantitative PCR, the authors confirmed recurrent amplification of OTX2 in both medulloblastoma cell lines (D425Med) and primary tumors. In the parallel study published by Di et al., ${ }^{35}$ OTX2 amplification was revealed in the D458Med cell line, also by digital karyotyping. In addition, by using data from SAGE libraries and quantitative RT-PCR, OTX2 (homeobox protein OTX2) was shown to be specifically overexpressed in medulloblastomas, especially lesions of anaplastic histology, as compared with a wide variety of other malignancies. Furthermore, the inhibition of OTX2 expression by siRNA-mediated knockdown or all-trans retinoic acid (ATRA) repressed medulloblastoma cell growth in vitro, suggesting that OTX2 may represent an attractive target for therapy, particularly in medulloblastomas of the anaplastic subtype.

Among the first authors to apply aCGH to medulloblastomas were Mendrzyk et al., ${ }^{104}$ who profiled 47 primary cases. These authors confirmed typical cytogenetic abnormalities including gains of chromosomes $17 \mathrm{q}, 7$, and 1q as well as losses of 17p, 11p, 10q, and 8. Importantly, they also identified a minimal region of recurrent, highlevel amplification targeting the CDK6 protooncogene on chromosome 7q21.2. They validated $C D K 6$ copy number aberrations by using FISH and established a negative correlation between moderate-high CDK6 protein expression and overall survival by measuring CDK6 status on a medulloblastoma TMA.

Note that FOXG1 is another candidate gene implicated in medulloblastoma pathogenesis given its recurrent gain on $14 \mathrm{q} 12$ as revealed by aCGH analysis. ${ }^{1}$ Adesina et al. ${ }^{1}$ have analyzed a small panel of medulloblastomas 
TABLE 1: Most prominent cytogenetic aberrations in medulloblastoma

\begin{tabular}{ccccc}
\hline \multicolumn{2}{c}{ Gains } & & \multicolumn{2}{c}{ Losses } \\
\cline { 1 - 2 } \cline { 5 - 5 } Chromosome & Frequency $(\%)^{*}$ & & Chromosome & Frequency $(\%)^{*}$ \\
\hline $1 q$ & 19 & & $8 p$ & 12 \\
$2 p$ & 20 & & $9 q$ & 10 \\
7 & 24 & & $10 q$ & 18 \\
$17 q$ & 44 & & $11 p$ & 14 \\
$i(17 q)$ & 30 & & $16 q$ & 12 \\
& & & $17 p$ & 36 \\
\hline
\end{tabular}

* Frequency based on results of 500,000 SNP array profilings of 122 primary medulloblastomas.

using a combination of conventional CGH (19 cases) and aCGH ( 9 cases) and reported a gain of the FOXG1 locus in 6 of 9 cases in the test set and 55 of 59 cases in a validation series of tumors. Expression of FOXG1 (forkhead box protein G1) correlated with the gene copy number and inversely correlated with p21 protein levels, a relationship that was strengthened in vitro as siRNA-mediated knockdown of FOXG1 in DAOY medulloblastoma cells resulted in increased $\mathrm{p} 21$ expression.

Amplifications of MYCL1, PDGFRA, and KIT-all protooncogenes not previously reported to be targeted in medulloblastoma-were also noted using aCGH technology. ${ }^{100}$ Amplicons targeting these cancer genes have since been observed in our SNP array studies and by others, suggesting that they are relevant oncogenes in medulloblastoma. ${ }^{92,119}$

An earlier aCGH study of medulloblastoma focused on a series of 16 primary cases and 3 medulloblastoma cell lines..$^{70}$ The authors noted a novel region of homozygous deletion on chromosome 6q23 in the DAOY cell line that targeted only 2 previously uncharacterized genes, both of which exhibited reduced expression in a large percentage of primary medulloblastomas analyzed. Our group has since validated this region of homozygous deletion in DAOY and functionally confirmed L3MBTL3 as a putative medulloblastoma tumor suppressor gene mapping to this locus. ${ }^{119}$

Medulloblastomas can be histologically classified into 5 recognizable subtypes: classic, desmoplastic, anaplastic, large-cell, and medulloblastoma with extensive nodularity. ${ }^{55}$ Classic medulloblastoma is by far the most common, followed by the desmoplastic subtype, which makes up 10-20\% of cases, and large-cell and anaplastic tumors, which account for $\sim 5-10 \%$ of cases. Although there is considerable variability in terms of patient outcome between the different histological subtypes and although histological staging has proven to be a less than ideal method of stratification, there is a great deal of interest in defining their molecular basis. To gain an improved understanding of the genomics of desmoplastic medulloblastomas, Ehrbrecht et al. ${ }^{39}$ performed conventional CGH on a set of 22 sporadic cases of this subtype, followed by aCGH on a subset. In their analysis, novel regions of amplification were reported on chromosomes $9 \mathrm{p}$ and $17 \mathrm{q} 22-24$, implicating candidate oncogenes in
TABLE 2 : Candidate oncogenes recurrently amplified in medulloblastoma

\begin{tabular}{lll}
\hline \multicolumn{1}{c}{ Gene } & Cytoband & \multicolumn{1}{c}{ Reference(s) } \\
\hline MYCL1 & $1 \mathrm{p} 34.2$ & $82,92,100,119$ \\
MYCN & $2 \mathrm{p} 24.3$ & $82,119,126$, and many others \\
PDGFRA & $4 \mathrm{q} 12$ & 100,119 \\
KIT & $4 \mathrm{q} 12$ & 100,119 \\
TERT & $5 \mathrm{p} 15.33$ & 38,136 \\
CDK6 & $7 \mathrm{q} 21.2$ & 104,119 \\
MYST3 & $8 \mathrm{p} 11.21$ & 119 \\
MYC & $8 \mathrm{q} 24.21$ & $82,119,126$, and many others \\
JMJD2C & $9 \mathrm{p} 24.1$ & 39,119 \\
miR-17/92 & $13 \mathrm{q} 31.3$ & 118,119 \\
IRS2 & $13 \mathrm{q} 34$ & 119 \\
FOXG1 & $14 \mathrm{q} 12$ & 1 \\
OTX2 & $14 \mathrm{q} 23.1$ & $21,35,119$ \\
\hline
\end{tabular}

these regions. Notably, JMJD2C was suggested as a putative oncogene mapping to the amplified region found on $9 \mathrm{p}$, and we have since identified it as recurrently amplified and overexpressed in an independent sample cohort and affecting the state of methylation on histone lysines in normal progenitor cells of the developing cerebellum (that is, CGNPs). ${ }^{119}$

There have been an impressive number of inquiries into the relationship between developmental signal transduction pathways and their role in medulloblastoma. $\mathrm{Mu}-$ tations in the Wnt, SHH, and Notch pathways have been well described in the medulloblastoma literature..$^{55,96}$ Nonetheless, a comprehensive understanding of how specific genomic events contribute to aberrant signaling of these pathways has not been established. An important finding relevant to deregulated Wnt signaling in medulloblastoma was reported in 2006 in 2 independent but related studies. ${ }^{28,154}$ Clifford et al. ${ }^{28}$ have profiled 19 primary medulloblastomas by aCGH, with the specific intent to genomically describe tumors with Wnt pathway activation (nuclear $\beta$-catenin; CTNNB1 or APC mutation). Interestingly, in both the initial cohort (19 cases) and a validation series (32 cases), a single copy deletion of chromosome 6 (monosomy 6) was found exclusively in the Wnt pathway tumors. Identical findings were reported by Thompson et al., ${ }^{154}$ who consistently observed a correlation between the Wnt pathway signature (Wnt pathway expression; CTNNB1 mutation) and markedly reduced expression of genes mapping to chromosome 6 because of deletion. Monosomy 6 is now widely accepted in the medulloblastoma community as a genomic marker of Wnt pathway tumors that is consistently associated with $C T N N B 1$ mutation. ${ }^{43,82,154}$ From a clinical perspective, monosomy $6 / C T N N B 1$ mutation is among the most reliable genetic markers in medulloblastoma, correlating with a highly favorable prognosis. ${ }^{28,43,52,126}$ Indeed, $100 \%$ of patients found to belong to the Wnt immunohistochemical category in the recent St Jude Medulloblastoma-96 clinical trial were event free at 5-years, compared with only $65 \%$ of patients in the SHH category. ${ }^{52}$ 
P. A. Northcott, J. T. Rutka, and M. D. Taylor

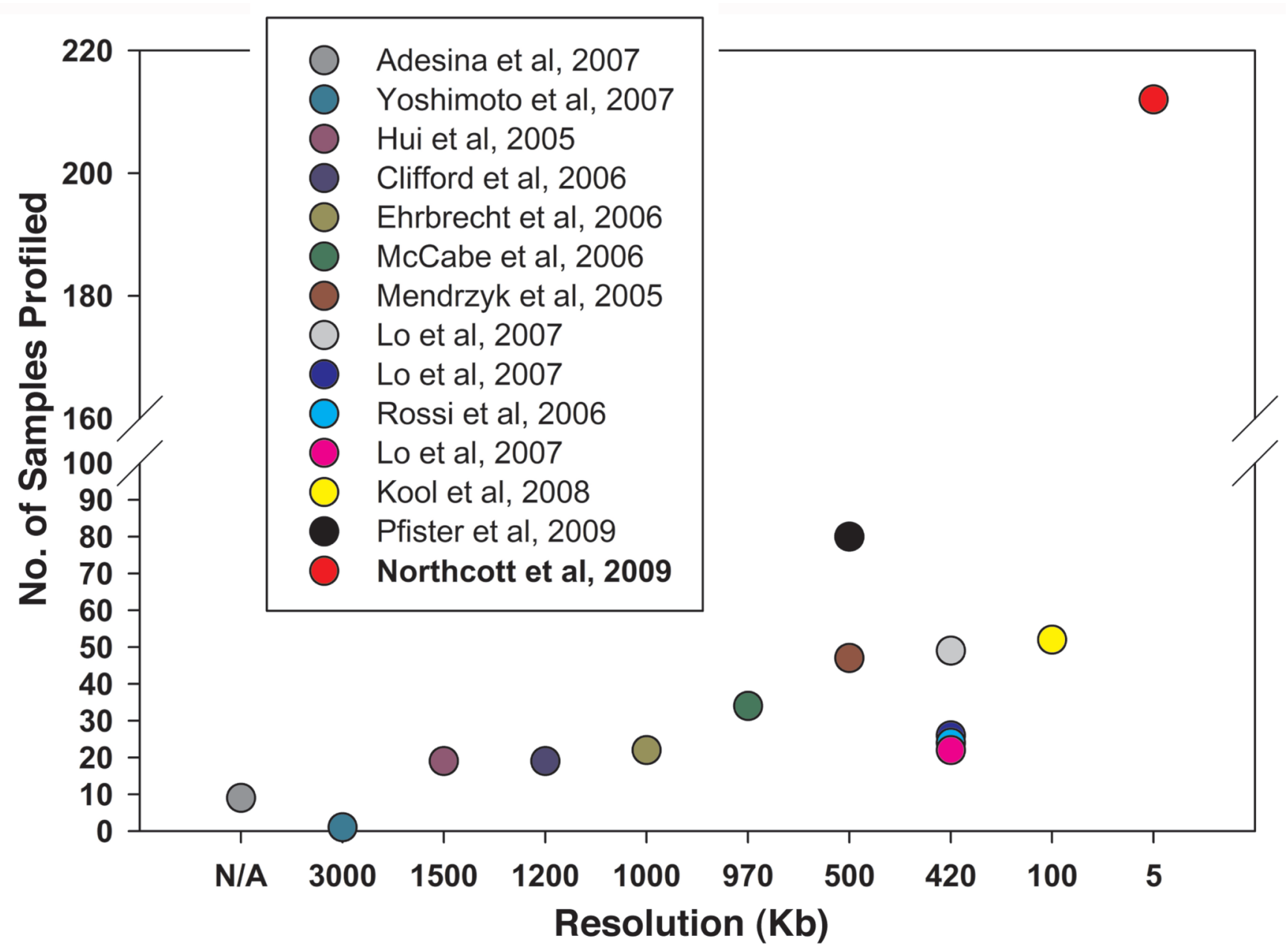

FIG. 3. Scatterplot identifying reports in the literature that have profiled medulloblastoma copy number aberrations using array-based genomic technologies. Each publication is represented as a colored circle, with its position along the y axis determined by the number of samples analyzed and its position along the $x$ axis determined by the approximate median resolution of the array platform(s) used in the study. Study referred to in figure is Northcott et al., 2009.119

Very recently, Pfister and colleagues ${ }^{126}$ proposed a model for molecular risk stratification of pediatric medulloblastoma based on DNA copy number aberrations affecting chromosomes 6q, 17q, and $M Y C / M Y C N$ loci. Using aCGH, the authors initially profiled 80 primary medulloblastomas in an attempt to identify genomic aberrations of prognostic value, and found a gain of chromosome 6q, amplification of $M Y C$ and $M Y C N$, isolated gain of $17 \mathrm{q}$, and $\mathrm{i}(17 \mathrm{q})$ all to be associated with a poor clinical outcome. In contrast, the loss of chromosome $6 q$ was indicative of an excellent prognosis, consistent with findings in the current literature..$^{28,43}$ Validation of these prognostic markers in a nonoverlapping set of 260 primary cases by using interphase FISH on a medulloblastoma TMA, Pfister et al. were able to establish an elegant staging system whereby patient outcome could be predicted based on the genomic status of only 4 markers (arranged from worst to best outcome): $M Y C / M Y C N$ amplification, $6 q$ gain, $17 q$ gain, $6 q / 17 q$ balanced, and $6 q$ loss.

Although several of the aCGH studies described above have been informative and have enhanced our understanding of the medulloblastoma genome, most have profiled relatively modest sample cohorts (median sample size: 24 cases) using arrays that-although an improvement over classic $\mathrm{CGH}$ - are of insufficient density and thus resolution (median resolution $\sim 500 \mathrm{~kb}$ ) to detect very focal genetic events. To address these caveats, we retrospectively collected an unprecedented cohort of 201 fresh-frozen primary medulloblastomas and 11 medulloblastoma cell lines and analyzed their genomes using high-resolution SNP genotyping arrays. ${ }^{119}$ These oligonucleotide arrays consisted of 25 mer probes designed to detect the genotype (that is, A or B allele) of known SNPs

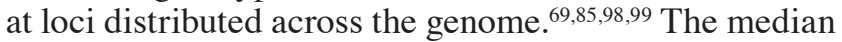
intermarker distances (that is, resolution) of probes on the 100,000 and 500,000 arrays used in this study were 8.5 and $2.5 \mathrm{~kb}$, respectively, which are at least an order of magnitude higher in terms of resolution than any previous array-based study of the medulloblastoma genome (Fig. 3 ). In addition to reporting cytogenetic gains and losses at frequencies already known in medulloblastoma (Fig. 4 and Table 1), this strategy of profiling a large number of samples on a high-resolution platform led to the identification of 191 high-level amplifications and 159 homozy- 


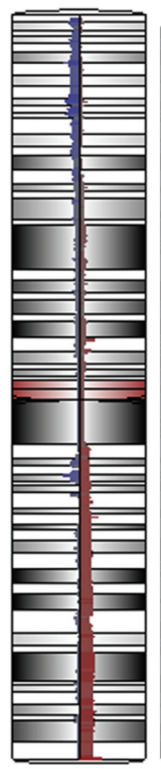

1

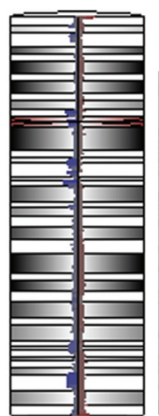

12

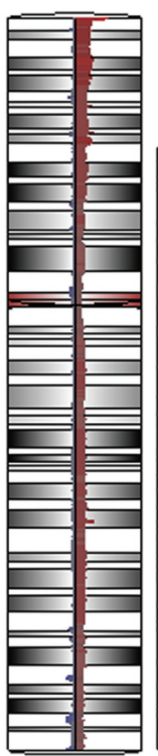

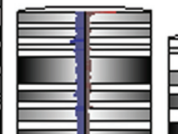
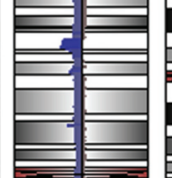
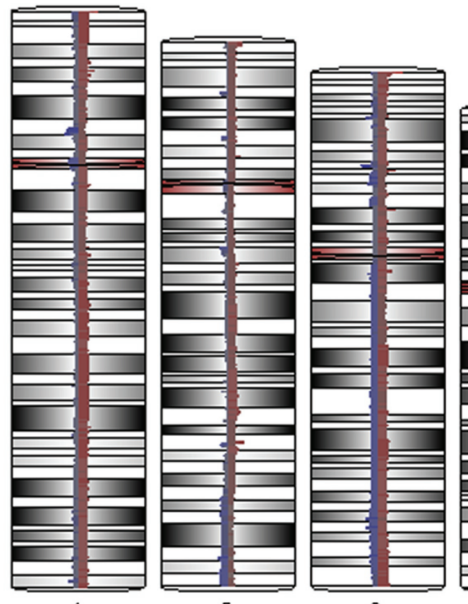

5

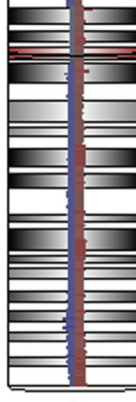

6
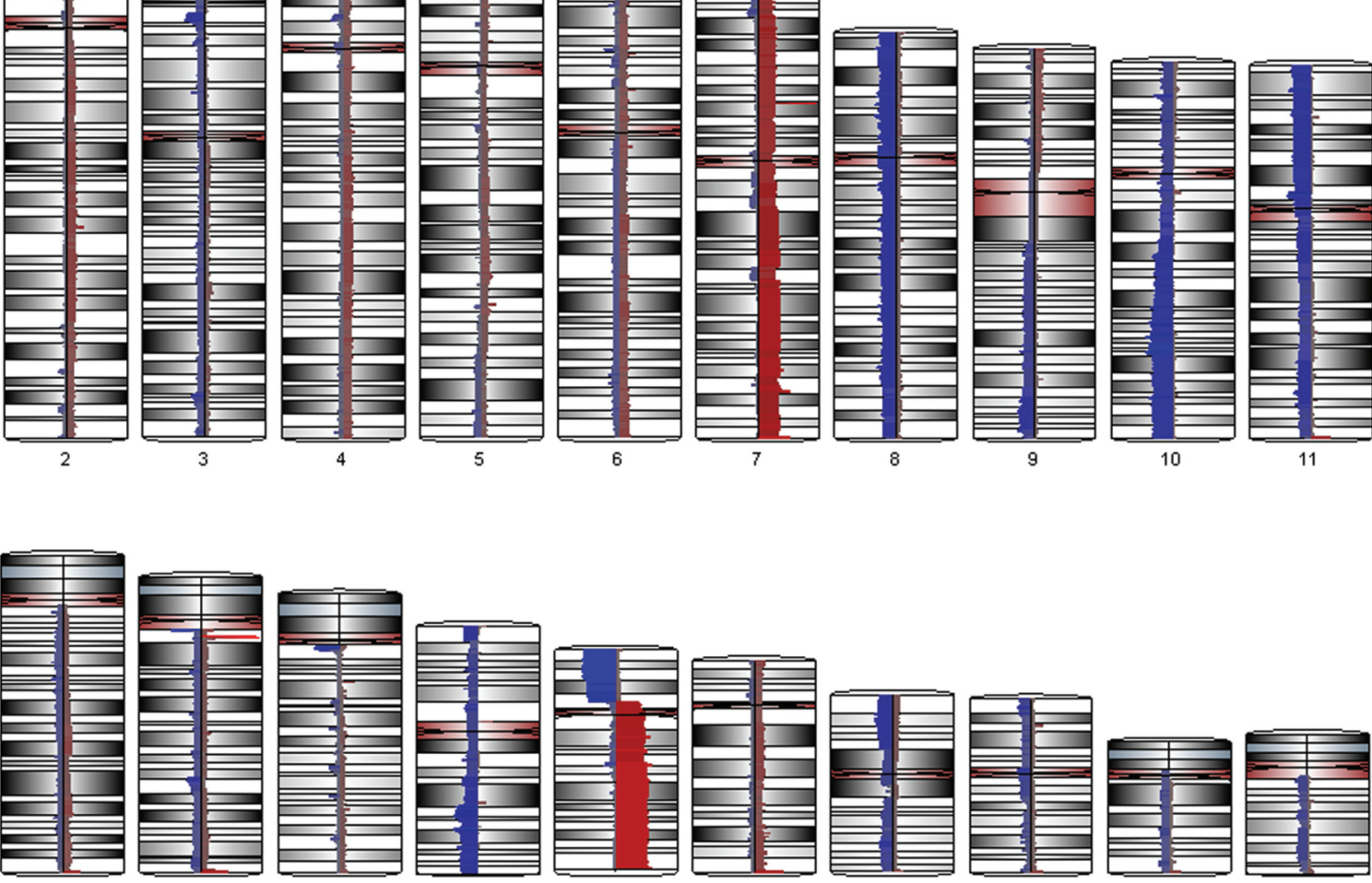

16

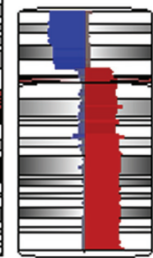

17

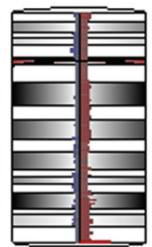

18

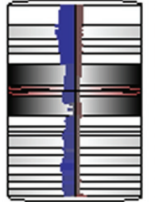

19

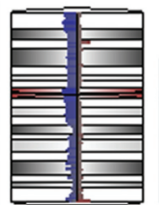

20

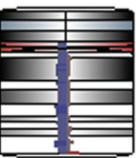

21

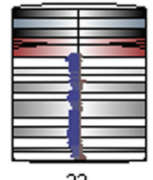

22

FIG. 4. Visual representation of gains and losses in the genome of medulloblastoma. High-resolution copy number data derived from 122 primary medulloblastomas is represented as a histogram for each of the 22 autosomes, with the relative frequency of gain depicted on the right of each chromosome in red, and the frequency of losses shown on the left of each chromosome in blue. The most frequent cytogenetic gains in this representative cohort are localized to chromosomes 1q, 7, and 17q, whereas recurrent losses are most notable on chromosomes $8,9 q, 10 q, 11,16 q$, and 17p.

gous deletions, most of which had not been reported in medulloblastoma. Surprisingly, only 12 recurrent amplifications were identified, and a mere 6 homozygous deletions were found in more than 1 sample. Of the recurrent homozygous deletions, EHMT1, a euchromatic histone (H3K9) methyltransferase, was the lone gene mapping to the minimal common region of a deleted region on chromosome 9q34, suggesting that it may represent a novel tumor suppressor gene in medulloblastoma. Note that EHMT1 functions as part of a transcriptional repressor complex that mediates gene silencing by promoting dimethylation of $\mathrm{H} 3 \mathrm{~K} 9\left(\mathrm{H} 3 \mathrm{~K} 9 \mathrm{me}^{2}\right),{ }^{121,150}$ a repressive epigenetic modification, ${ }^{16,84}$ in the promoter regions of target genes. The expression of EHMT1 was shown to be significantly downregulated at both the mRNA and protein level, and staining for both EHMT1 and $\mathrm{H} 3 \mathrm{~K} 9 \mathrm{me}^{2}$ on a medulloblastoma TMA showed a significant correlation between EHMT1 status and the H3K9 methylation state, consistent with a model in which the loss of EHMT1 leads to H3K9 hypomethylation in medulloblastoma. In addition to EHMT1, 7 other genes with a putative role in the regulation of histone lysine methylation were also found to be the target of focal copy number aberrations in the data set, including SMYD4, L3MBTL2, L3MBTL3, SCML2, JMJD2C, JMJD2B, and MYST3. Recurrent targeting of genes sharing a common role in the modulation of histone lysine residues in medulloblastoma suggests that deregulation of the histone code, particularly histone lysine methylation, very likely contributes to the pathogenesis of at least some medulloblastomas.

\section{Medulloblastoma Transcriptome Profiling}

Typically, strategies aimed at the transcriptional profiling of cancer have involved the comparison of gene expression signatures obtained for normal and neoplastic tissues (Fig. 5). In one of the earliest studies of medulloblastoma gene expression profiling, Michiels et al. ${ }^{107}$ used SAGE to compare genes expressed in medulloblastoma 


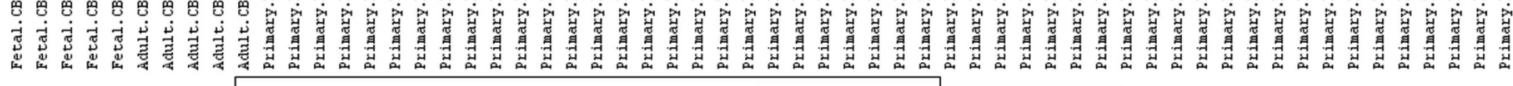

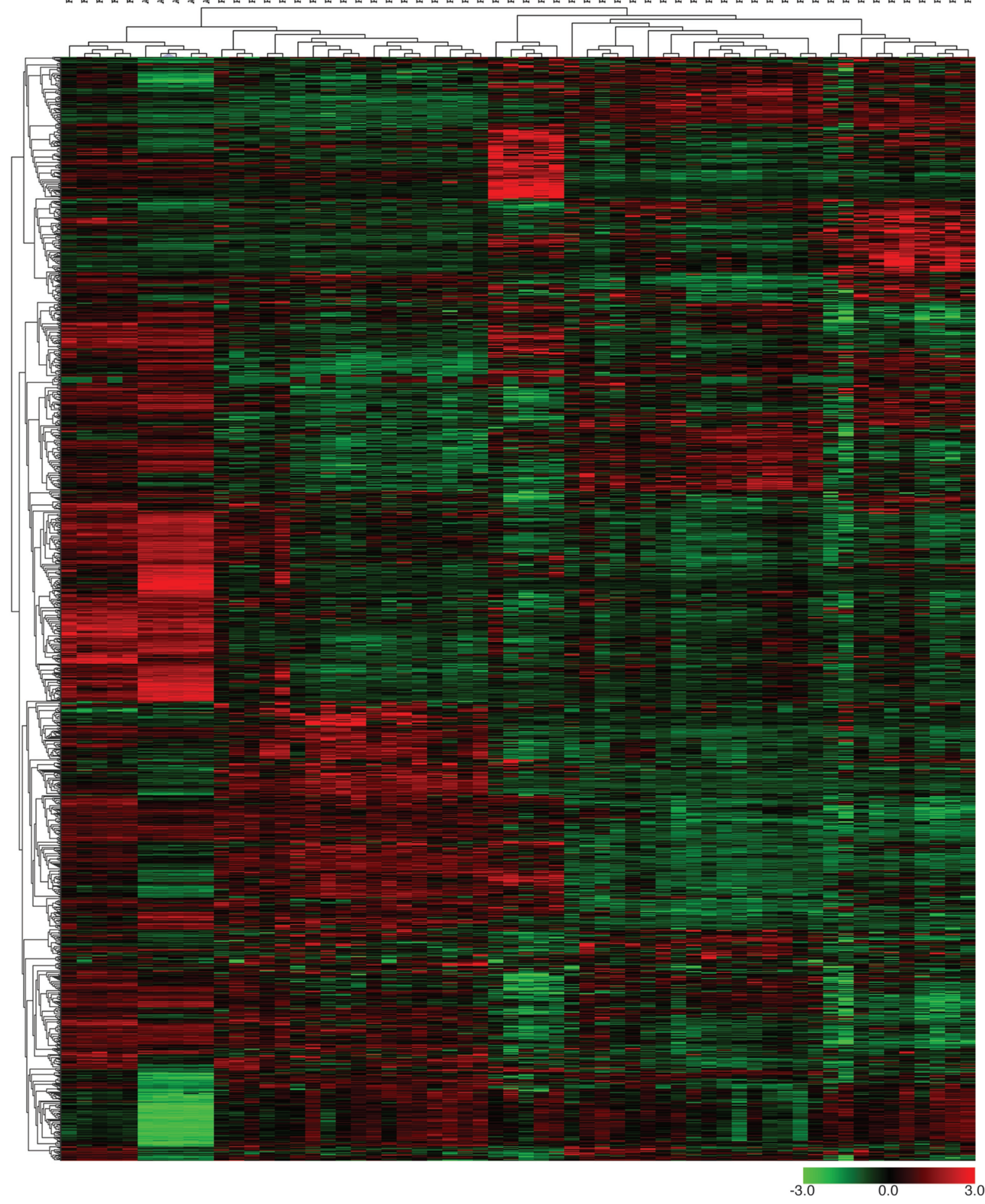

FIG. 5. Heatmap showing gene expression data for 10 normal cerebellum (CB) samples ( 5 fetal and 5 adult) and 50 primary medulloblastomas analyzed using Affymetrix arrays. Genes exhibiting elevated expression are shown in red, whereas genes with reduced expression are depicted in green. Unsupervised hierarchical clustering of samples using the most differentially expressed genes results in a clear distinction between normal cerebellar samples and primary tumors. 


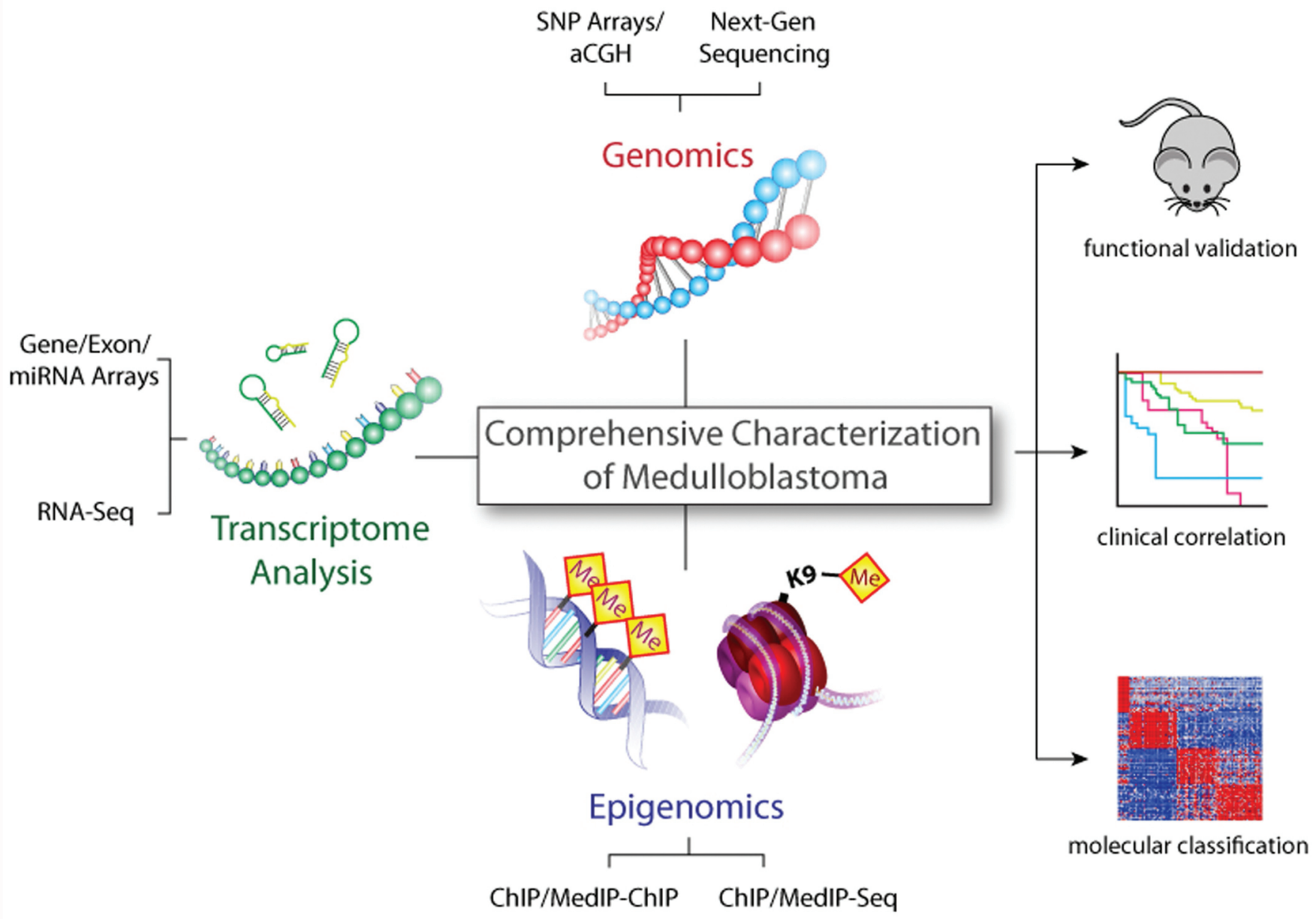

FIG. 6. Schematic illustrating how collaborative approaches that involve integration of genomics, transcriptome analysis, and epigenomics will be applied in the future characterization of medulloblastoma. For each category, some of the leading technologies of the present and future are listed, with applications relying on NGS (Next-Gen Sequencing) present in each. The union of these orthogonal genome/transcriptome/epigenome interrogation strategies will greatly accelerate the identification of novel candidate genes and pathways involved in medulloblastoma genesis and permit follow-up functional validation studies, correlation with clinical variables, and improved molecular classification.

with those in the fetal brain (24.5 weeks). Serial analysis of gene expression uses DNA sequencing technology to digitally quantify mRNA abundance by counting the frequency with which a short sequence tag (that is, transcript) appears in a cDNA library. ${ }^{161,162}$ Serial analysis of gene expression technology is very effective in quantifying gene expression and in identifying novel genes/transcripts, as no a priori knowledge of the genome under study is required. ${ }^{131,144,159,160}$ In the study by Michiels and colleagues, $\sim 10,000$ tags were sequenced in both medulloblastoma and fetal brain, with $\sim 6000$ unique genes identified in each transcriptome. A comparison of the SAGE data revealed 138 genes with significant differential expression between the 2 sources, including ZIC1 (zinc finger protein ZIC 1) and OTX2, both showing significantly elevated expression in medulloblastoma that was confirmed by Northern blotting in multiple independent samples. As these genes are highly expressed in cerebellar germinal zones (that is, the external granule layer and subventricular zone), this study provided early clues into the origins of medulloblastoma.
The presence of disseminated disease at diagnosis is a strong, independent indicator of a poor prognosis for medulloblastoma, occurring in $\sim 1$ of every 3 cases. ${ }^{52,83,152,177}$ Therefore, understanding the molecular basis of metastatic medulloblastoma is extremely important clinically. The first study to specifically compare metastatic (M+) with nonmetastatic (M0) medulloblastoma at a gene expression level was performed by MacDonald and colleagues in $2001 .{ }^{94}$ Twenty-three primary medulloblastomas designated as either M+ or M0 were analyzed using Affymetrix G110 cancer arrays, which identified 85 genes as differentially expressed between the 2 classes. Using a supervised class prediction algorithm, this 85gene signature classified the M+ and M0 tumors with $72 \%$ accuracy. Interestingly, PDGFR and members of the Ras/MAPK signaling cascade were reported to be significantly upregulated in metastatic versus nonmetastatic cases. The overexpression of PDGFR in metastatic disease was confirmed by immunohistochemistry in an independent set of tumors. In vitro assays performed in the DAOY medulloblastoma cell line showed that the 
PDGF ligand activated the Ras/MAPK pathway and promoted cell migration in this system, whereas neutralizing antibodies against PDGFR attenuated MAPK signaling and prevented ligand-mediated migration. In a follow-up study by Gilbertson and Clifford, ${ }^{54}$ the association between PDGFR overexpression and metastatic medulloblastoma was confirmed, further supporting the validity of this pathway as a candidate for targeted therapy.

Undoubtedly, one of the most seminal papers in medulloblastoma genomics was written by Pomeroy and colleagues, ${ }^{132}$ who surveyed the expression profiles of a large series of primary brain tumors and made at least 3 findings of clinical significance. Initially, 42 samples consisting of medulloblastomas (10 patients), atypical teratoid rhabdoid tumors (5 patients), renal and extrarenal rhabdoid tumors (5 patients), sPNETs (8 patients), and nonembryonal brain tumors (malignant glioma; 10 patients), and normal human cerebellum (4 patients) were analyzed using Affymetrix HuGeneFl arrays containing $\sim 6000$ known genes. Based on differentially expressed transcripts, these authors showed a clear distinction between the different tumor types, establishing that histologically similar tumors such as medulloblastomas and SPNETs were molecularly distinct. The molecular distinction between medulloblastomas and sPNETs has important clinical implications; because of their similar histology, these tumors were historically classified under the same broad category of PNET and thus were treated with the same protocols. ${ }^{141}$ In recent years, however, it has become evident that medulloblastomas and sPNETs are both molecularly and biologically distinct, with sPNETs typically exhibiting a worse prognosis. ${ }^{31,89,100,127,137,155}$

These same authors also compared the expression profiles in a set of 34 medulloblastomas of either classic (25 cases) or desmoplastic (9 cases) histology, revealing a notable degree of statistically significant differential expression between the 2 subtypes. Genes signifying desmoplastic medulloblastoma included PTCH, GLI, MYCN, and $I G F 2$, all of which are now well-described targets of SHH signaling. Although a link between mutations in the SHH pathway and medulloblastoma pathogenesis had already been discovered, this study was among the first to document an association between aberrant SHH signaling and sporadic desmoplastic medulloblastoma.

A third key finding in this study stemmed from the authors' use of gene expression data to predict the outcome of 60 patients with medulloblastoma for whom clinical follow-up data were available. Using a class prediction algorithm, an 8-gene classification model was generated and successfully predicted the survival status for 47 of the 60 patients profiled. Genes correlated with a favorable outcome included markers of cerebellar differentiation $(\beta-N A P, N S C L 1$, and TRKC) as well as genes encoding components of the extracellular matrix (lysyl hydroxylase $[P L O D]$, collagen Type Vai, and elastin). In contrast, genes associated with a poor outcome included those with a role in cell proliferation and metabolism (MYBL2, enolase $1, L D H, H M G 1[Y]$, and cytochrome $\mathrm{C}$ oxidase) as well as ribosomal protein-encoding genes. Much like the study by MacDonald et al. ${ }^{94}$ described earlier, the report by Pomeroy and colleagues ${ }^{132}$ demonstrates the utility of correlating gene expression profiles in medulloblastoma with a particular phenotype (that is, favorable vs poor outcome) and provides a rationale for the incorporation of similar molecular profiling strategies in the future diagnosis and treatment of patients with medulloblastoma.

Following the Pomeroy study, a number of independent groups, including our own, have engaged in medulloblastoma transcriptome profiling efforts using a variety of technologies. ${ }^{22,79,115,123,175}$ Boon et al. ${ }^{22}$ used SAGE to analyze 20 primary medulloblastomas, identifying 30 transcripts exhibiting elevated expression in tumors compared with normal cerebellum and additional regions of the brain. The cancer-testis antigen PRAME, CD24,PRL, TOP2A, MYCN, and BARHL1 were all overexpressed in this study. Data from more recent array-based studies by our group have confirmed the aberrant expression of cancer-testis antigens from the $M A G E$ and $G A G E$ families in medulloblastoma cell lines and in some primary samples, suggesting that these genes may be important in medulloblastoma. ${ }^{79}$

In an earlier study we used suppression subtractive hybridization to identify genes deregulated in both human and mouse $\left(\mathrm{Ptc}^{+/}\right)$medulloblastoma compared with normal, species-matched cerebellum. ${ }^{175}$ In suppression subtractive hybridization, double-stranded cDNA libraries are first prepared from tester (that is, medulloblastoma) and driver (that is, normal cerebellum) RNA samples. ${ }^{164}$ Heat-denatured tester cDNA is subsequently digested, adapter ligated, and then hybridized with the denatured driver cDNA to generate a subtracted cDNA library that is PCR amplified and cloned into a recipient plasmid for bacterial transformation and sequencing of clones for gene identification. In this effort, over 100 upregulated cDNA fragments were identified in the human library, including ULIP (also known as DPYSL3), SOX4, NNAT, and the previously implicated BARHL1 and OTX2 genes. In addition, genes identified as upregulated in medulloblastomas from $\mathrm{Ptc}^{+/-}$mice included CCND2, TMPO, Musashi-1, and others.

Another informative expression profile of medulloblastoma was generated by Neben et al., ${ }^{115}$ who analyzed $\sim 4200$ genes in 35 primary medulloblastomas in an attempt to identify those associated with patient outcome. Based on mRNA levels, 54 genes were shown to be markers of poor outcome, and a subset of these (9 genes) was further evaluated by immunohistochemistry in a nonoverlapping set of 180 cases on a medulloblastoma TMA. Of these candidate genes, STK15 positivity was identified as a negative prognostic marker of overall survival, whereas other putative markers implicated in the study (that is, cyclin D1 and stathmin 1) were not.

\section{Molecular Classification of Medulloblastoma}

Over the past decade, significant progress has been made in how we study the cancer genome. Indeed, gene expression profiling has proven to be an effective tool for the molecular classification of cancer, including brain tumors. ${ }^{57,109,120,132}$ Following the studies of Macdonald and Pomeroy, Thompson et al. ${ }^{154}$ were the first to truly 
establish the existence of unique molecular subgroups of medulloblastoma using gene expression data. Profiling a series of 46 primary medulloblastomas, these authors performed unsupervised hierarchical clustering with the most informative genes in the data set, identifying 5 molecular subgroups of medulloblastoma. By integrating immunohistochemistry, FISH, and mutational screening data generated from these samples, it was shown that molecular subgroups of medulloblastoma have specific genomic and genetic features. Importantly, this study was the first to demonstrate that Wnt (that is, monosomy 6 and CTNNBI mutation) and SHH tumors (that is, $P$ TCHI and $S U F U$ mutation) are mutually exclusive.

In a more recent study, Kool et al. ${ }^{82}$ utilized a similar integrative genomics approach to further characterize molecular subgroups of medulloblastoma. By combining array-based gene expression and copy number profiles for 52 primary cases, Kool and colleagues recapitulated the 5 molecular subgroups described by Thompson et al. ${ }^{11}$ and correlated the different subgroups with specific genomic and clinical features. Importantly, the authors furthered our knowledge of non-Wnt/SHH tumors (subgroups A and $\mathrm{B}$ ), showing that the 3 remaining subgroups $(\mathrm{C}, \mathrm{D}$, and E) are closely related and marked by elevated expression of neuronal differentiation (subgroups $\mathrm{C}$ and D) and retinal (subgroups D and E) genes. Furthermore, metastatic disease was shown to be more highly associated with subgroups C, D, and E, providing further support for the potential stratification of patients based on molecular subgrouping.

\section{Beyond Protein-Coding Genes: miRNAs in Medulloblastoma}

Over the course of the past 5 or so years, there has been a literal explosion in the miRNA field, especially with respect to elucidating their role in human diseasein particular, cancer. ${ }^{24,41,64}$ Small, noncoding, singlestranded RNA molecules, miRNAs posttranscriptionally regulate gene expression through their interaction with complementary sequences in the $3^{\prime}$ untranslated regions of target mRNAs.,10 Target mRNAs are either degraded or translationally repressed by specific miRNAs, depending on the degree of complementarity between the miRNA and its target. Despite an intense amount of investigation into the involvement of miRNAs in a variety of cancer types, knowledge of their role in medulloblastoma pathogenesis is still in its infancy. The few studies of the entire miRNAome that have been conducted to date are discussed below.

Ferretti and colleagues ${ }^{45}$ recently performed a TaqMan quantitative RT-PCR-based profiling of $248 \mathrm{miR}$ NAs in a panel of medulloblastomas (14 cases) and normal cerebellar controls (7 cases), reporting an overwhelming bias toward downregulation of miRNAs in tumors versus controls. A subset of 86 miRNAs previously reported to be expressed in neuronal tissues and/or implicated in cancer were further analyzed in a larger cohort of tumors (34 cases), with the authors selecting miR-9 and miR-125a as 2 neuronal candidates downregulated in medulloblastoma for functional studies. The expression of both miR-9 and miR-125a was induced by retinoic acid treatment of D283 medulloblastoma cells, an agent known to inhibit medulloblastoma cell proliferation. In addition, ectopic overexpression of miR-9 and miR-125a inhibited proliferation, impaired anchorage-independent growth, and promoted apoptosis of D283 cells. Truncated trkC was identified as a target for posttranscriptional repression by both miR-9 and miR-125a in this study, suggesting a possible correlation between the loss of miR-9/miR-125a and the upregulation of the proproliferative truncated trkC in medulloblastoma.

In an effort to discriminate miRNAs deregulated in SHH-driven medulloblastomas from non-SHH cases, the same group of authors ${ }^{44}$ used the Glil expression status to stratify a panel of 31 medulloblastomas into 2 classes (Gli1 $^{\text {high }}$ and Gli1 ${ }^{\text {low }}$ ) before profiling a set of 250 miRNAs using TaqMan-based quantitative RT-PCR. This approach revealed a set of 34 miRNAs exhibiting significant differential expression between the 2 classes. Three candidates exhibiting reduced expression in Gli1 ${ }^{\text {high }}$ tumorsmiR-125b, miR-324-5p, and miR-326-were chosen for functional analysis based on their predicted capacity to target and repress the SHH family members, Smo and Gli1. Indeed, all 3 candidates were shown to repress Smo mRNA levels when overexpressed in DAOY medulloblastoma cells. Additionally, the expression of these candidate miRNAs correlated with the differentiation state of cultured CGNPs, presumed cells of origin for SHHdriven medulloblastomas, ${ }^{14,47,55}$ and their ectopic expression reduced SHH-mediated proliferation and promoted neurite outgrowth in the same cell type.

In 2 distinct but parallel comprehensive analyses of the human and mouse medulloblastoma miRNAomes, the $m i R-17 / 92$ polycistron was identified as a putative medulloblastoma oncogene. ${ }^{18,158}$ A bona fide oncogene in B-cell lymphoma, $m i R-17 / 92$ has been reported to be aberrantly expressed in a variety of human tumors. ${ }^{66,103}$ To identify miRNAs deregulated in mouse models of medulloblastoma, Uziel et al.$^{158}$ performed unbiased NGS to quantify miRNA abundance in medulloblastoma cells isolated from spontaneous tumors of $\mathrm{Ink}_{4} \mathrm{c}^{-/-} ; \mathrm{Ptc}^{+-}$or Ink $4 c^{-/-}$; and $p 53^{-/-}$genotypes as compared with wildtype control cerebellum (1 month old) and CGNPs (6 days old). This strategy revealed 26 miRNAs with elevated expression and 24 with reduced expression in the tumor models. Among upregulated miRNAs in murine medulloblastoma cells, miR-17/92 and related paralogs accounted for 9 of 26. In addition, the authors provided evidence that miR-17/92 might cooperate with SHH signaling in medulloblastoma, showing preferential upregulation of miR-17/92 in the SHH subtype by quantitative RT-PCR profiling of a small panel of human tumors (5 SHH lesions and 5 non-SHH lesions). To evaluate its oncogenic potential in a context relevant to $\mathrm{SHH}$-driven medulloblastoma, miR-17/92 was retrovirally transduced into 6-day-old CGNPs isolated from both Ink $4 \mathrm{c}^{-1-}, \mathrm{Ptc}^{+/-}$and Ink $4 c^{-/-}, p 53^{-/-}$mice prior to orthotopic transplantation of miR-17/92-expressing CGNPs into immunocompromised mice. Notably, only cells derived from the $\mathrm{Ptc}^{+-}$ background developed medulloblastoma (9 of 9 cases) in this model. Furthermore, tumor cells were sensitive to 
the Smo inhibitor cyclopamine, exhibited elevated Math1 and Glil mRNA levels, and lost expression of the wildtype Ptc allele-all markers of activated SHH signaling and supportive of a synergistic connection between miR$17 / 92$ and SHH in these tumors.

As detailed earlier, we recently performed high-resolution SNP array profiling on a group of $>200$ medulloblastomas. ${ }^{119}$ This effort revealed multiple regions of previously unreported copy number aberrations in the medulloblastoma genome, including recurrent, high-level amplification of miR-17/92 on chromosome 13q31.118,119 Subsequent interphase FISH performed on a medulloblastoma TMA consisting of a nonoverlapping series of tumors confirmed miR-17/92 amplification in 6\% of cases. To gain further insight into the role of miRNAs in medulloblastoma, we next used miRNA microarrays to globally profile the human medulloblastoma miRNAome in a series of 90 primary medulloblastomas and 10 normal cerebellar controls (5 fetal and 5 adult samples). Remarkably, miR-17/92 and related paralogs (miR-106a/363 and miR-106b/25) were identified as the most highly upregulated miRNAs in medulloblastoma when compared with normal cerebellum in this analysis. The combination of miR-17/92 amplification and consistent overexpression suggested miR-17/92 as a key player in medulloblastoma pathogenesis.

As shown by the aforementioned studies of Thompson $^{154}$ and Kool, ${ }^{82}$ medulloblastomas can be classified into unique molecular subgroups based on distinct gene expression signatures and specific genomic and genetic features ${ }^{82,154}$ Using Affymetrix exon arrays to comprehensively profile the transcriptome of the same 90 primary medulloblastomas analyzed by miRNA microarray, we described 4 distinct molecular subgroups of medulloblastoma. ${ }^{118}$ These subgroups include the well-characterized Wnt and SHH subgroups described earlier, as well as 2 independent subgroups we have designated Groups $\mathrm{C}$ and D. Through the integration of genomics (copy number), mRNA, and miRNA expression, we found that miR-17/92 was most highly expressed in SHH-driven medulloblastomas, in agreement with the observations reported by Uziel and colleagues. ${ }^{158}$ Additionally, we showed elevated miR-17/92 levels in tumors exhibiting high MYCN (SHH) and MYC (Group C, Wnt) expression, indicative of miR$17 / 92$ transcriptional upregulation by N-Myc and Myc and confirming miR-17/92 aberrancy in a large percentage of human medulloblastomas $(\sim 60 \%)$. Deregulation of miR17/92 was conserved in well-characterized, SHH-driven mouse models of medulloblastoma-Ptc ${ }^{+-}$and SmoAlalso in concordance with the findings mentioned above. Finally, using CGNPs isolated from wild-type mice, we showed that miR-17/92 is transcriptionally induced by SHH through N-Myc, maintains CGNPs in a proliferative state in the absence of $\mathrm{SHH}$, and synergizes with $\mathrm{SHH}$ to enhance CGNP cell growth. Cumulatively, the results of Uziel et al. and our own strongly support miR-17/92 as a legitimate medulloblastoma oncogene that cooperates with SHH signaling to promote and/or enhance CGNP proliferation.

\section{Beyond Genomics: the Medulloblastoma Epigenome}

Until recently, the majority of cancer research efforts had focused on describing the genetic basis of cancer, studying everything from large cytogenetic aberrations to SNPs and mutations. Over the past few years, however, there has been an ever-growing volume of literature linking the deregulation of epigenetics to malignancy. $23,42,75,76,156$ Epigenetics is defined as "mitotically heritable changes in gene expression that are not accompanied by modifications in primary DNA sequence." Epigenetic modifications include DNA methylation on cytosine residues, most often in the context of $\mathrm{CpG}$ dinucleotides, as well as posttranslational modification of histone proteins, such as methylation, acetylation, phosphorylation, and ubiquitination. ${ }^{16,84}$ Hypermethylation of $\mathrm{CpG}$ islands located at the $5^{\prime}$ end of genes has been reported in most cancers and, either alone or in combination with genetic mechanisms (that is, gene deletion or mutation), can contribute to tumor suppressor gene silencing. Although a handful of known tumor suppressors can be silenced by promoter methylation in medulloblastoma by using candidate gene approaches (that is, HICl, RASSF 1A, and CASP8), ,88,61,65, $68,91,93,140,166$ the application of unbiased, whole-epigenome strategies to identify novel candidates have been scant to date, consisting of only those instances described in the few published reports mentioned below.

Among the earliest studies to implicate aberrant promoter methylation in medulloblastoma on a global scale was an effort led by Frühwald and colleagues ${ }^{49}$ who used the technique of restriction landmark genomic scanning to analyze DNA methylation patterns in 17 primary medulloblastomas and 5 medulloblastoma cell lines. Using this method, the authors identified methylation in up to $1 \%$ of all $\mathrm{CpG}$ islands in primary tumors and up to $6 \%$ in medulloblastoma cell lines. In addition, an association between hypermethylated sequences in medulloblastoma and a poor prognosis was implied. Collectively, these findings provided early evidence that epigenetic events are likely to play a role in medulloblastoma pathogenesis.

In a study using microarray-based differential methylation hybridization, Waha et al. ${ }^{165}$ identified hypermethylation of the SCG5 (secretory granule, neuroendocrine protein 1 [7B2 protein] gene) in $16(\sim 70 \%)$ of 23 primary medulloblastomas and 7 ( 87\%) of 8 medulloblastoma cell lines. Differential methylation hybridization involves a series of enzymatic digestions with methylation-insensitive followed by methylation-sensitive restriction enzymes, and uncut (methylated) fragments are PCRamplified before hybridization to microarrays containing probes designed to interrogate $\mathrm{CpG}$ islands throughout the genome. ${ }^{174}$ The expression of SCG5 was found to be downregulated in the majority of primary samples and cell lines as compared with normal cerebellar controls, and SCG5 transcription was restored in cell lines treated with the demethylating agent, 5-aza (5-aza-2'-deoxycytidine). Furthermore, the reexpression of SCG5 in the D283Med cell line resulted in growth suppression and reduced colony formation, suggesting that SCG5 may be a putative tumor suppressor gene in medulloblastoma. 
Pfister and colleagues ${ }^{128}$ developed and applied a technique known as array-based profiling of referenceindependent methylation status (aPRIMES) to globally survey DNA methylation patterns in the medulloblastoma genome. This technique compares 2 differentially digested (methylation-sensitive and methylation-specific) aliquots from the same sample genome by competitive hybridization to a $\mathrm{CpG}$ island microarray. The advantage of using test-versus-test as opposed to test-versus-control hybridization is the avoidance of both the influences of tissue-specific methylation that may be present in the control sample and the genomic aberrations that may exist in the test sample and not in the control genome. Using this methodology, Pfister et al. showed a striking association between samples classified as either "low methylators" or "high methylators" and patient outcome, with the highmethylator group exhibiting reduced overall survival. In addition, the GLI C2H2-type zinc-finger protein family member ZIC2 was identified as a hypermethylated candidate using aPRIMES and was subsequently confirmed to be epigenetically silenced in a panel of primary medulloblastomas by using a combination of pyrosequencing and quantitative RT-PCR analysis.

In 2 technically similar yet independent genomewide methylation studies conducted by Anderton et al. ${ }^{4}$ and Kongkham et al., ${ }^{81}$ 5-aza-treated medulloblastoma cell lines were profiled on Affymetrix expression arrays in an effort to uncover novel tumor suppressor genes silenced by aberrant promoter methylation. In the report by Anderton and colleagues, 3 medulloblastoma cell lines (D425Med, D283Med, and MED8A) were either left untreated or exposed to 5-aza, and transcripts showing increased expression by microarray in response to the DNA methyltransferase inhibitor were investigated further by bioinformatically confirming the presence of a $5^{\prime} \mathrm{CpG}$ island and assessing methylation status through bisulfite sequencing. ${ }^{4}$ This approach combined with gene expression analysis identified COLIA2 as an epigenetically silenced candidate in medulloblastoma that is preferentially inactivated in nondesmoplastic and noninfant ( $>3$ years) desmoplastic cases.

Kongkham et al. ${ }^{81}$ performed a similar genome-wide 5 -aza screen in a larger group of 9 medulloblastoma cell lines but incorporated multiple additional criteria when filtering identified candidate genes as compared with those in the Anderton et al. ${ }^{4}$ study. These authors selected for further analysis those genes that demonstrated in at least 2 cell lines a $>2$-fold upregulation in expression following 5-aza treatment, contained a predicted $\mathrm{CpG}$ island in their promoter region, and were identified as targets of loss of heterozygosity based on SNP genotyping studies. ${ }^{119}$ Under these criteria, SPINT2, a negative regulator of the HGF/Met signaling pathway, was identified, exhibiting robust reexpression in 6 of the 9 medulloblastoma cell lines profiled. The authors confirmed the downregulation of SPINT2 in a significant percentage of primary medulloblastomas ( $>2$-fold in 41 of 56 samples) analyzed by quantitative RT-PCR, and, importantly, that aberrant promoter methylation (assessed by methylation-specific PCR) correlated with the observed reduction in gene expression in most cases. Stable reexpression of SPINT2 in medulloblastoma cell lines resulted in the attenuation of the malignant phenotype, inhibiting cell proliferation, anchorage-independent growth in soft agar, and cell motility. Furthermore, the orthotopic transplantation of D283 cells stably reexpressing SPINT2 into recipient nude mice significantly delayed the time to death compared with empty vector control cells in an intracerebellar xenograft model. These data strongly implicate SPINT2 as a putative tumor suppressor gene in medulloblastoma and shed further light on the apparent role of aberrant HGF/Met signaling in medulloblastoma etiology.

Collectively, these recent studies of the medulloblastoma epigenome have proven informative and have further implicated epigenetic gene silencing as an important mechanism of tumor suppressor gene inactivation in medulloblastoma. The future application of strategies that enrich for epigenetic modifications (that is, methylationdependent immunoprecipitation [MedIP] or chromatin immunoprecipitation [ChIP]) combined with high-resolution microarrays or NGS technologies will probably lead to an improved appreciation of the role that epigenetics plays in medulloblastoma.

\section{Next-Generation Genomics of Medulloblastoma}

Over the past few years, microarray technologies have significantly increased our understanding of the medulloblastoma genome, transcriptome, and, to some extent, epigenome. Moving forward, array platforms will undoubtedly continue to be used in genome-wide profiling of medulloblastoma, especially as the resolution and coverage of these methods continue to improve and the cost of these screens remains affordable. However, recent breakthroughs in DNA sequencing technologies have taken the genomics community by storm, and their application in medulloblastoma research is, without question, imminent.

Since the early 1990s, the capillary-based Sanger method of DNA sequencing has been the mainstay for most applications in molecular biology, even the first drafts of the human genome published in 2000. ${ }^{86,163}$ More recently, conventional sequencing has been successfully used in large-scale resequencing efforts, profiling anywhere from a few hundred genes to all known proteincoding genes in a single cancer genome. ${ }^{26,36,77,78,125,173}$ Indeed, initial exon resequencing of the colorectal, breast, pancreatic, and glioblastoma multiforme genomes has revealed new genes and pathways involved in the pathogenesis of the respective cancer types. ${ }^{77,78,125,173}$ However, these studies relied on the PCR-mediated amplification of literally hundreds of thousands of exons combined with an enormous workload of conventional sequencing, unrealistic tasks for most of the cancer genomics community.

Fortunately, over the last few years a revolution in DNA sequencing technology has occurred and is rapidly changing the field of cancer genomics..$^{33,143,145,146}$ Next-generation (also known as "next-gen" or "deep") sequencing biochemistries now permit the parallel acquisition of up to 10 s of gigabases $(\mathrm{Gb})$ of DNA sequence of variable "read" length in a single experiment. Multiple NGS options are currently available-454 genome sequencer 
(Roche), gene analyzer (Solexa/Illumina), SOLiD system (Applied Biosystems) ${ }^{5,146}$ —each with its own strengths and weaknesses. The repertoire and capabilities of these platforms are continually improving. For example, the SOLiD 3 System currently boasts $>20 \mathrm{~Gb}$ of DNA sequence per run, compared with $\sim 750-1000$ bp generated using traditional Sanger sequencing. Although the cost/ base ratio is significantly lower for next-generation technologies, the current cost of a single SOLiD 3 run is in the neighborhood of $\$ 15,000$ (vs $\sim \$ 5$ for conventional sequencing), making next-generation tools prohibitively expensive for a large percentage of the research community, especially when considering the sequencing of large numbers of patient samples.

The biochemistry and real-time imaging-based data acquisition involved in NGS are what allow these technologies the parallel, high-throughput capacity that is not feasible with conventional Sanger sequencing; detailed reviews on the technical principles of conventional sequencing and NGS have been reported.5,106,111,146 In the Sanger method, DNA to be sequenced is either randomly fragmented and cloned into a high-copy number plasmid prior to bacterial transformation (shotgun sequencing) or PCR-amplified using target-specific primers (gene-specific sequencing). The amplified template is then subjected to a series of sequencing cycles whereby the template is denatured, primers are annealed, and a new complementary strand is synthesized in the presence of fluorescentlabeled dideoxynucleotide triphosphates ([ddNTPs], 1 unique color for each of the 4). End-labeled DNA fragments are subsequently separated using high-resolution capillary electrophoresis followed by laser excitation of labeled fragment ends, with the emission spectra producing a 4-color chromatogram that can be translated into DNA sequence. Modern Sanger sequencing units can simultaneously run samples in 96- or 384-well format, generating reads of up to $1000 \mathrm{bp}$ in length per sample and providing some degree of throughput.

Despite differences in template amplification and sequencing biochemistry associated with current next-generation platforms, the principles and workflow involved in these technologies are relatively similar. Initially, a template library is prepared through random DNA fragmentation and adapter ligation. Ligated fragments are then bound to micron-sized beads (Roche and Applied Biosystems) or a planar substrate (Solexa/Illumina) and PCR amplified (that is, emulsion PCR or bridge PCR) as clusters or colonies consisting of thousands of clonal "features" to be sequenced. An array or flow-cell can consist of literally millions of clustered features, enabling massively parallel downstream sequencing. So-called sequencing-by-synthesis is then performed with either a polymerase (Roche and Solexa/Illumina) or ligase (Applied Biosystems) that serially extends primed templates. Light (pyrosequencing with Roche) or fluorescence (Solexa/Illumina and Applied Biosystems) emitted following the incorporation of dNTPs (deoxynucleoside triphosphates) or oligonucleotides is then captured by imaging the full array of synthesized features at the end of each cycle. The final result of a full next-generation run currently ranges from up to $\sim 1,000,000,000$ reads of $\sim 400$ bp with Roche, $\sim 150,000,000$ reads of 35 bp with Solexa/Illumina, and $\sim 300,000,000$ reads of $50 \mathrm{bp}$ with the Applied Biosystems. These figures translate into 10s of $\mathrm{Gb}$ of DNA sequence in a single run (1 human genome comprises $\sim 3 \mathrm{~Gb}$ ), allowing for high-coverage, whole-genome sequencing on 1 machine within a few weeks - this in sharp contrast to the sequencing "factories" and several years required for the initial Sanger-based sequencing of the human genome not more than a decade ago.

Multiple "proof-of-principle" studies using next-generation technology have now been performed to analyze the various aspects of both normal and cancer genomes. Published reports have described array-based, targeted capture, and NGS of $\sim 200,000$ protein-coding exons in the human genome, allowing specific identification of both common and rare sequence variants. ${ }^{67,116}$ Unbiased, whole-genome NGS has also been reported for multiple normal human genomes ${ }^{15,80,167,171}$ and, recently, the acute myeloid leukemia genome from a single individual. ${ }^{88}$ Producing nearly 100 billion bases of sequence, authors of the acute myeloid leukemia study described 10 genes with acquired somatic mutations that were not present in the patient-matched genome from normal skin cells.

Perhaps equally impressive, NGS has not been limited to studies aimed at the identification of sequence variants and mutations..$^{5,111}$ Structural aberrations, including inter- and intrachromosomal rearrangements (inversions, inverted/tandem duplications, and translocations) as well as copy number aberrations (amplifications and deletions), have been identified in human cancer cells using NGS, with improved specificity and sensitivity compared with array-based methods..$^{25,27}$ Whole-transcriptome profiling (also known as RNA-Seq) has also been described using next-generation approaches, permitting the quantification of transcript abundance (mRNA, miRNA, and so forth) and the identification of novel genes and isoforms in an unbiased manner. ${ }^{110,113,114,122,169,172}$ In contrast to the arraybased technologies used in gene expression analyses, RNA-Seq requires no a priori knowledge of the transcriptome under investigation-thus enabling full-transcriptome characterization - and eliminates biases associated with array content. Similarly, unbiased NGS has been extended to studies of the mammalian epigenome, including genome-wide analyses of DNA methylomes, ${ }^{37,102}$ mapping of histone modifications, ${ }^{9,108}$ and detailing of the locations of DNA-binding proteins. ${ }^{74,139}$

Collectively, these emerging NGS-based approaches for studying the cancer genome hold great promise for comprehensive analyses of medulloblastoma. As the cost and bioinformatics involved in next-generation become more mainstream, next-generation-based profiling of the medulloblastoma genome, transcriptome, and epigenome will surely be the priority of several investigative groups (Fig. 6). Undoubtedly, these efforts will lead to a more complete understanding of the genes and pathways involved in the initiation, maintenance, and progression of medulloblastoma. Moreover, as larger patient cohorts are gathered and profiled using these advanced methods, more specific and reliable molecular classification of medulloblastoma will probably be possible. Finally, the correlation of genomic data with patient clinical data, 
such as the presence of metastatic disease and overall survival, will undoubtedly be improved.

\section{Conclusions}

Twenty years of studying the medulloblastoma genome has facilitated a detailed description of the medulloblastoma karyotype, led to the identification and validation of bona fide oncogenes and tumor suppressors, and implicated key signaling pathways and networks that are recurrently deregulated. Much of the recent progress in this field is owed to improvements in the technologies available for analyzing the genome. To comprehensively appreciate a cancer genome such as medulloblastoma, unbiased, high-resolution, genome-wide investigations must be undertaken, ideally using a combination of complementary (microarrays and NGS) and integrative (genome, transcriptome, and epigenome) technologies. Of course, an adequate sample size is critical to such studies if a full range of both common and rare genomic changes is to be captured. Large, coordinated multiinstitutional consortiums such as The Cancer Genome Atlas (TCGA) are now applying this philosophy to study the genomes of brain (glioblastoma multiforme), lung (squamous carcinoma), and ovarian (serous cystadenocarcinoma) cancers. ${ }^{26}$ As part of their pilot project, TCGA is profiling large numbers of tumors of these origins to assess aberrations in DNA sequence (substitutions and indels), genomic copy number (amplifications and deletions), chromosomal composition (rearrangements), DNA methylation (hyperand hypo-promoter methylation), and gene expression (aberrant expression and splicing). Results from TCGA and other similar large-scale collaborative efforts utilizing this type of broad approach to cancer genomics have recently demonstrated success. ${ }^{26,36,78,125}$ To make progress in the fine genomic mapping of medulloblastoma, analogous strategies are warranted.

The generation of large genomic data sets of medulloblastoma using multiple orthogonal technologies will have its challenges. A logistical issue facing potential large-scale genomic projects on medulloblastoma relates to the immensity of the bioinformatics involved, as profiling large sample cohorts inevitably produces large amounts of data of varying complexity. The integration of multiple genomic data sets for maximal extraction of biological information will be a major priority if these new technologies are to be used to their full potential. In addition, the use of NGS technology for cancer genomics studies is still in its infancy, and the cost as well as the bioinformatics and computing challenges related to this promising technology remain a significant hurdle. Before NGS can be efficiently applied to large-scale medulloblastoma projects, financial feasibility and informatics considerations must be addressed.

Discriminating between so-called driver and passenger mutations is also a common yet critical dilemma in cancer genomics studies. ${ }^{124,149}$ In other words, not all somatic alterations in a cancer genome actually contribute to cancer development and confer a clonal advantage to a tumor cell. Distinguishing genes that provide a clonal advantage (drivers) in tumorigenesis from those that do not (passengers) requires the integration of multiple data types (copy number, sequencing, and expression) and, ideally, functional validation-neither of which is a simple task when considering possibly hundreds of candidate cancer genes. Thus, the use of genomic studies alone will be insufficient for determining the genes "driving" medulloblastomas, and follow-up functional studies, including mouse models, will be a necessity.

A third issue to consider is the reality of intratumoral heterogeneity and how global profiling strategies are typically performed using nucleic acid extracted from bulk tumor tissue. Methods such as array-based copy number and gene expression profiling essentially produce an average for a genomic region or gene in a given template. Since medulloblastomas are neither histologically nor molecularly monoclonal, genomic events that are present in only a small percentage of cells will be under-called or missed outright when bulk tumor is the source of the template queried. Indeed, the amplification of known medulloblastoma oncogenes, such as $M Y C$ and $M Y C N$, is often found in only $10-20 \%$ of cells as determined by FISH (S. Pfister, personal communication, 2009), suggesting that these events are under-called by array profiling. Strategies that involve the analysis of distinct cell populations (that is, laser capture microdissection and cell sorting) or even single cells within a tumor will be required to avoid losing potentially valuable genetic information present only in tumor cell subpopulations.

Despite these relevant technical and logistical considerations, the next few years promise to be an exciting period for the community studying medulloblastoma. Large-scale, collaborative genomics projects will provide a more detailed characterization of this genome than ever before, and, optimistically, many new candidates will be uncovered. These efforts should continue to improve our ability to diagnose, stratify, and treat medulloblastoma, eventually leading to decreased deaths and improved quality of life for patients.

\section{Disclosure}

The authors report no conflict of interest concerning the materials or methods used in this study or the findings specified in this paper.

\section{Acknowledgments}

The authors sincerely thank Paul Paroutis and Christian Smith for assistance with artwork and figure preparation.

\section{References}

1. Adesina AM, Nguyen Y, Mehta V, Takei H, Stangeby P, Crabtree S, et al: FOXG1 dysregulation is a frequent event in medulloblastoma. J Neurooncol 85:111-122, 2007

2. Aldosari N, Wiltshire RN, Dutra A, Schrock E, McLendon RE, Friedman HS, et al: Comprehensive molecular cytogenetic investigation of chromosomal abnormalities in human medulloblastoma cell lines and xenograft. Neuro Oncol 4:75-85, 2002

3. Ambros V: The functions of animal microRNAs. Nature 431:350-355, 2004

4. Anderton JA, Lindsey JC, Lusher ME, Gilbertson RJ, Bailey $\mathrm{S}$, Ellison DW, et al: Global analysis of the medulloblastoma 
epigenome identifies disease-subgroup-specific inactivation of COL1A2. Neuro Oncol 10:981-994, 2008

5. Ansorge WJ: Next-generation DNA sequencing techniques. $\mathbf{N}$ Biotechnol 25:195-203, 2009

6. Attard TM, Giglio P, Koppula S, Snyder C, Lynch HT: Brain tumors in individuals with familial adenomatous polyposis: a cancer registry experience and pooled case report analysis. Cancer 109:761-766, 2007

7. Avet-Loiseau H, Vénuat AM, Terrier-Lacombe MJ, LellouchTubiana A, Zerah M, Vassal G: Comparative genomic hybridization detects many recurrent imbalances in central nervous system primitive neuroectodermal tumours in children. $\mathbf{B r} \mathbf{J}$ Cancer 79: 1843-1847, 1999

8. Badiali M,Pession A, Basso G, Andreini L, Rigobello L, Galassi $\mathrm{E}$, et al: N-myc and c-myc oncogenes amplification in medulloblastomas. Evidence of particularly aggressive behavior of a tumor with c-myc amplification. Tumori 77:118-121, 1991

9. Barski A, Cuddapah S, Cui K, Roh TY, Schones DE, Wang Z, et al: High-resolution profiling of histone methylations in the human genome. Cell 129:823-837, 2007

10. Bartel DP: MicroRNAs: target recognition and regulatory functions. Cell 136:215-233, 2009

11. Bayani J, Squire JA: Traditional banding of chromosomes for cytogenetic analysis. Curr Protoc Cell Biol Chapter 22:Unit 22.3, 2004

12. Bayani J, Zielenska M, Marrano P, Kwan Ng Y, Taylor MD, Jay $\mathrm{V}$, et al: Molecular cytogenetic analysis of medulloblastomas and supratentorial primitive neuroectodermal tumors by using conventional banding, comparative genomic hybridization, and spectral karyotyping. J Neurosurg 93:437-448, 2000

13. Bayani JM, Squire JA: Applications of SKY in cancer cytogenetics. Cancer Invest 20:373-386, 2002

14. Behesti H, Marino S: Cerebellar granule cells: insights into proliferation, differentiation, and role in medulloblastoma pathogenesis. Int J Biochem Cell Biol 41:435-445, 2009

15. Bentley DR, Balasubramanian S, Swerdlow HP, Smith GP, Milton J, Brown CG, et al: Accurate whole human genome sequencing using reversible terminator chemistry. Nature 456:53-59, 2008

16. Bernstein BE, Meissner A, Lander ES: The mammalian epigenome. Cell 128:669-681, 2007

17. Biegel JA, Rorke LB, Packer RJ, Sutton LN, Schut L, Bonner $\mathrm{K}$, et al: Isochromosome $17 \mathrm{q}$ in primitive neuroectodermal tumors of the central nervous system. Genes Chromosomes Cancer 1:139-147, 1989

18. Bigner SH, Friedman HS, Vogelstein B, Oakes WJ, Bigner DD: Amplification of the c-myc gene in human medulloblastoma cell lines and xenografts. Cancer Res 50:2347-2350, 1990

19. Bigner SH, Mark J, Friedman HS, Biegel JA, Bigner DD: Structural chromosomal abnormalities in human medulloblastoma. Cancer Genet Cytogenet 30:91-101, 1988

20. Bigner SH, McLendon RE, Fuchs H, McKeever PE, Friedman HS: Chromosomal characteristics of childhood brain tumors. Cancer Genet Cytogenet 97:125-134, 1997

21. Boon K, Eberhart CG, Riggins GJ: Genomic amplification of orthodenticle homologue 2 in medulloblastomas. Cancer Res 65:703-707, 2005

22. Boon K, Edwards JB, Siu IM, Olschner D, Eberhart CG, Marra MA, et al: Comparison of medulloblastoma and normal neural transcriptomes identifies a restricted set of activated genes. Oncogene 22:7687-7694, 2003

23. Brena RM, Costello JF: Genome-epigenome interactions in cancer. Hum Mol Genet 16 (Spec No 1):R96-R105, 2007

24. Calin GA, Croce CM: MicroRNA signatures in human cancers. Nat Rev Cancer 6:857-866, 2006

25. Campbell PJ, Stephens PJ, Pleasance ED, O’Meara S, Li H, Santarius T, et al: Identification of somatically acquired rearrangements in cancer using genome-wide massively parallel paired-end sequencing. Nat Genet 40:722-729, 2008
26. Cancer Genome Atlas Research Network: Comprehensive genomic characterization defines human glioblastoma genes and core pathways. Nature 455:1061-1068, 2008

27. Chiang DY, Getz G, Jaffe DB, O'Kelly MJ, Zhao X, Carter SL, et al: High-resolution mapping of copy-number alterations with massively parallel sequencing. Nat Methods 6:99-103, 2009

28. Clifford SC, Lusher ME, Lindsey JC, Langdon JA, Gilbertson RJ, Straughton D, et al: Wnt/Wingless pathway activation and chromosome 6 loss characterize a distinct molecular subgroup of medulloblastomas associated with a favorable prognosis. Cell Cycle 5:2666-2670, 2006

29. Cogen PH, Daneshvar L, Metzger AK, Duyk G, Edwards MS, Sheffield VC: Involvement of multiple chromosome 17p loci in medulloblastoma tumorigenesis. Am J Hum Genet 50:584-589, 1992

30. Cogen PH, Daneshvar L, Metzger AK, Edwards MS: Deletion mapping of the medulloblastoma locus on chromosome 17p. Genomics 8:279-285, 1990

31. Cohen BH, Zeltzer PM, Boyett JM, Geyer JR, Allen JC, Finlay JL, et al: Prognostic factors and treatment results for supratentorial primitive neuroectodermal tumors in children using radiation and chemotherapy: a Childrens Cancer Group randomized trial. J Clin Oncol 13:1687-1696, 1995

32. Cohen N, Betts DR, Tavori U, Toren A, Ram T, Constantini $\mathrm{S}$, et al: Karyotypic evolution pathways in medulloblastoma/ primitive neuroectodermal tumor determined with a combination of spectral karyotyping, G-banding, and fluorescence in situ hybridization. Cancer Genet Cytogenet 149:44-52, 2004

33. Coombs A: The sequencing shakeup. Nat Biotechnol 26: 1109-1112, 2008

34. Davies JJ, Wilson IM, Lam WL: Array CGH technologies and their applications to cancer genomes. Chromosome Res 13:237-248, 2005

35. Di C, Liao S, Adamson DC, Parrett TJ, Broderick DK, Shi Q, et al: Identification of OTX2 as a medulloblastoma oncogene whose product can be targeted by all-trans retinoic acid. Cancer Res 65:919-924, 2005

36. Ding L, Getz G, Wheeler DA, Mardis ER, McLellan MD, Cibulskis K, et al: Somatic mutations affect key pathways in lung adenocarcinoma. Nature 455:1069-1075, 2008

37. Down TA, Rakyan VK, Turner DJ, Flicek P, Li H, Kulesha E, et al: A Bayesian deconvolution strategy for immunoprecipitation-based DNA methylome analysis. Nat Biotechnol 26:779-785, 2008

38. Eberhart CG, Kratz JE, Schuster A, Goldthwaite P, Cohen KJ, Perlman EJ, et al: Comparative genomic hybridization detects an increased number of chromosomal alterations in large cell/anaplastic medulloblastomas. Brain Pathol 12: 36-44, 2002

39. Ehrbrecht A, Müller U, Wolter M, Hoischen A, Koch A, Radlwimmer B, et al: Comprehensive genomic analysis of desmoplastic medulloblastomas: identification of novel amplified genes and separate evaluation of the different histological components. J Pathol 208:554-563, 2006

40. Ellison DW, Clifford SC, Gajjar A, Gilbertson RJ: What's new in neuro-oncology? Recent advances in medulloblastoma. Eur J Paediatr Neurol 7:53-66, 2003

41. Esquela-Kerscher A, Slack FJ: Oncomirs-microRNAs with a role in cancer. Nat Rev Cancer 6:259-269, 2006

42. Esteller M: Epigenetics in cancer. N Engl J Med 358:11481159,2008

43. Fattet S, Haberler C, Legoix P, Varlet P, Lellouch-Tubiana A, Lair S, et al: Beta-catenin status in paediatric medulloblastomas: correlation of immunohistochemical expression with mutational status, genetic profiles, and clinical characteristics. J Pathol 218:86-94, 2009 
44. Ferretti E, De Smaele E, Miele E, Laneve P, Po A, Pelloni M, et al: Concerted microRNA control of Hedgehog signalling in cerebellar neuronal progenitor and tumour cells. EMBO J 27:2616-2627, 2008

45. Ferretti E, De Smaele E, Po A, Di Marcotullio L, Tosi E, Espinola MS, et al: MicroRNA profiling in human medulloblastoma. Int J Cancer 124:568-577, 2009

46. Finlay JL, Erdreich-Epstein A, Packer RJ: Progress in the treatment of childhood brain tumors: no room for complacency. Pediatr Hematol Oncol 24:79-84, 2007

47. Fogarty MP, Kessler JD, Wechsler-Reya RJ: Morphing into cancer: the role of developmental signaling pathways in brain tumor formation. J Neurobiol 64:458-475, 2005

48. Friedman HS, Burger PC, Bigner SH, Trojanowski JQ, Brodeur GM, He XM, et al: Phenotypic and genotypic analysis of a human medulloblastoma cell line and transplantable xenograft (D341 Med) demonstrating amplification of c-myc. Am J Pathol 130:472-484, 1988

49. Frühwald MC, O'Dorisio MS, Dai Z, Tanner SM, Balster DA, Gao X, et al: Aberrant promoter methylation of previously unidentified target genes is a common abnormality in medulloblastomas-implications for tumor biology and potential clinical utility. Oncogene 20:5033-5042, 2001

50. Fults DW: Modeling medulloblastoma with genetically engineered mice. Neurosurg Focus 19(5):E7, 2005

51. Gailani MR, Bale SJ, Leffell DJ, DiGiovanna JJ, Peck GL, Poliak S, et al: Developmental defects in Gorlin syndrome related to a putative tumor suppressor gene on chromosome 9 . Cell 69:111-117, 1992

52. Gajjar A, Chintagumpala M, Ashley D, Kellie S, Kun LE, Merchant TE, et al: Risk-adapted craniospinal radiotherapy followed by high-dose chemotherapy and stem-cell rescue in children with newly diagnosed medulloblastoma (St Jude Medulloblastoma-96): long-term results from a prospective, multicentre trial. Lancet Oncol 7:813-820, 2006

53. Gajjar A, Hernan R, Kocak M, Fuller C, Lee Y, McKinnon PJ, et al: Clinical, histopathologic, and molecular markers of prognosis: toward a new disease risk stratification system for medulloblastoma. J Clin Oncol 22:984-993, 2004

54. Gilbertson RJ, Clifford SC: PDGFRB is overexpressed in metastatic medulloblastoma. Nat Genet 35:197-198, 2003

55. Gilbertson RJ, Ellison DW: The origins of medulloblastoma subtypes. Annu Rev Pathol 3:341-365, 2008

56. Gilhuis HJ, Anderl KL, Boerman RH, Jeuken JM, James $\mathrm{CD}$, Raffel C, et al: Comparative genomic hybridization of medulloblastomas and clinical relevance: eleven new cases and a review of the literature. Clin Neurol Neurosurg 102: 203-209, 2000

57. Golub TR, Slonim DK, Tamayo P, Huard C, Gaasenbeek M, Mesirov JP, et al: Molecular classification of cancer: class discovery and class prediction by gene expression monitoring. Science 286:531-537, 1999

58. Gonzalez-Gomez P, Bello MJ, Inda MM, Alonso ME, Arjona $\mathrm{D}$, Amiñoso C, et al: Deletion and aberrant $\mathrm{CpG}$ island methylation of Caspase 8 gene in medulloblastoma. Oncol Rep 12:663-666, 2004

59. Griffin CA, Hawkins AL, Packer RJ, Rorke LB, Emanuel BS: Chromosome abnormalities in pediatric brain tumors. Cancer Res 48:175-180, 1988

60. Grimmer MR, Weiss WA: Childhood tumors of the nervous system as disorders of normal development. Curr Opin Pediatr 18:634-638, 2006

61. Grotzer MA, Eggert A, Zuzak TJ, Janss AJ, Marwaha S, Wiewrodt BR, et al: Resistance to TRAIL-induced apoptosis in primitive neuroectodermal brain tumor cells correlates with a loss of caspase-8 expression. Oncogene 19:4604-4610, 2000

62. Hahn H, Wicking C, Zaphiropoulous PG, Gailani MR, Shanley S, Chidambaram A, et al: Mutations of the human homolog of Drosophila patched in the nevoid basal cell carcinoma syndrome. Cell 85:841-851, 1996

63. Hamilton SR, Liu B, Parsons RE, Papadopoulos N, Jen J, Powell SM, et al: The molecular basis of Turcot's syndrome. $\mathbf{N}$ Engl J Med 332:839-847, 1995

64. Hammond SM: MicroRNAs as oncogenes. Curr Opin Genet Dev 16:4-9, 2006

65. Harada K, Toyooka S, Maitra A, Maruyama R, Toyooka KO, Timmons CF, et al: Aberrant promoter methylation and silencing of the RASSF1A gene in pediatric tumors and cell lines. Oncogene 21:4345-4349, 2002

66. He L, Thomson JM, Hemann MT, Hernando-Monge E, Mu $\mathrm{D}$, Goodson S, et al: A microRNA polycistron as a potential human oncogene. Nature 435:828-833, 2005

67. Hodges E, Xuan Z, Balija V, Kramer M, Molla MN, Smith SW, et al: Genome-wide in situ exon capture for selective resequencing. Nat Genet 39:1522-1527, 2007

68. Horiguchi K, Tomizawa Y, Tosaka M, Ishiuchi S, Kurihara H, Mori M, et al: Epigenetic inactivation of RASSF1 A candidate tumor suppressor gene at 3 p21.3 in brain tumors. Oncogene 22:7862-7865, 2003

69. Huang J, Wei W, Zhang J, Liu G, Bignell GR, Stratton MR, et al: Whole genome DNA copy number changes identified by high density oligonucleotide arrays. Hum Genomics 1:287299,2004

70. Hui AB, Takano H, Lo KW, Kuo WL, Lam CN, Tong CY, et al: Identification of a novel homozygous deletion region at 6q23.1 in medulloblastomas using high-resolution array comparative genomic hybridization analysis. Clin Cancer Res 11:4707-4716, 2005

71. International Human Genome Sequencing Consortium: Finishing the euchromatic sequence of the human genome. Nature 431:931-945, 2004

72. James CD, He J, Carlbom E, Mikkelsen T, Ridderheim PA, Cavenee WK, et al: Loss of genetic information in central nervous system tumors common to children and young adults. Genes Chromosomes Cancer 2:94-102, 1990

73. Jemal A, Siegel R, Ward E, Hao Y, Xu J, Murray T, et al: Cancer statistics, 2008. CA Cancer J Clin 58:71-96, 2008

74. Johnson DS, Mortazavi A, Myers RM, Wold B: Genomewide mapping of in vivo protein-DNA interactions. Science 316:1497-1502, 2007

75. Jones PA, Baylin SB: The epigenomics of cancer. Cell 128:683-692, 2007

76. Jones PA, Baylin SB: The fundamental role of epigenetic events in cancer. Nat Rev Genet 3:415-428, 2002

77. Jones S, Hruban RH, Kamiyama M, Borges M, Zhang X, Parsons DW, et al: Exomic sequencing identifies PALB2 as a pancreatic cancer susceptibility gene. Science 324:217, 2009

78. Jones S, Zhang X, Parsons DW, Lin JC, Leary RJ, Angenendt $\mathrm{P}$, et al: Core signaling pathways in human pancreatic cancers revealed by global genomic analyses. Science 321:1801-1806, 2008

79. Kasuga C, Nakahara Y, Ueda S, Hawkins C, Taylor MD, Smith CA, et al: Expression of MAGE and GAGE genes in medulloblastoma and modulation of resistance to chemotherapy. Laboratory investigation. J Neurosurg Pediatr 1:305-313, 2008

80. Kim JI, Ju YS, Park H, Kim S, Lee S, Yi JH, et al: A highly annotated whole-genome sequence of a Korean individual. Nature 460:1011-1015, 2009

81. Kongkham PN, Northcott PA, Ra YS, Nakahara Y, Mainprize TG, Croul SE, et al: An epigenetic genome-wide screen identifies SPINT2 as a novel tumor suppressor gene in pediatric medulloblastoma. Cancer Res 68:9945-9953, 2008

82. Kool M, Koster J, Bunt J, Hasselt NE, Lakeman A, van Sluis $\mathrm{P}$, et al: Integrated genomics identifies five medulloblastoma subtypes with distinct genetic profiles, pathway signatures and clinicopathological features. PLoS One 3:e3088, 2008

83. Kortmann RD, Kühl J, Timmermann B, Mittler U, Urban C, 
Budach V, et al: Postoperative neoadjuvant chemotherapy before radiotherapy as compared to immediate radiotherapy followed by maintenance chemotherapy in the treatment of medulloblastoma in childhood: results of the German prospective randomized trial HIT '91. Int J Radiat Oncol Biol Phys 46:269-279, 2000

84. Kouzarides T: Chromatin modifications and their function. Cell 128:693-705, 2007

85. LaFramboise T: Single nucleotide polymorphism arrays: a decade of biological, computational and technological advances. Nucleic Acids Res 37:4181-4193, 2009

86. Lander ES, Linton LM, Birren B, Nusbaum C, Zody MC, Baldwin J, et al : Initial sequencing and analysis of the human genome. Nature 409:860-921, 2001

87. Leary RJ, Cummins J, Wang TL, Velculescu VE: Digital karyotyping. Nat Protoc 2:1973-1986, 2007

88. Ley TJ, Mardis ER, Ding L, Fulton B, McLellan MD, Chen K, et al: DNA sequencing of a cytogenetically normal acute myeloid leukaemia genome. Nature 456:66-72, 2008

89. Li MH, Bouffet E, Hawkins CE, Squire JA, Huang A: Molecular genetics of supratentorial primitive neuroectodermal tumors and pineoblastoma. Neurosurg Focus 19(5):E3, 2005

90. Lindsey JC, Anderton JA, Lusher ME, Clifford SC: Epigenetic events in medulloblastoma development. Neurosurg Focus 19(5):E10, 2005

91. Lindsey JC, Lusher ME, Anderton JA, Bailey S, Gilbertson RJ, Pearson $\mathrm{AD}$, et al: Identification of tumour-specific epigenetic events in medulloblastoma development by hypermethylation profiling. Carcinogenesis 25:661-668, 2004

92. Lo KC, Rossi MR, Eberhart CG, Cowell JK: Genome wide copy number abnormalities in pediatric medulloblastomas as assessed by array comparative genome hybridization. Brain Pathol 17:282-296, 2007

93. Lusher ME, Lindsey JC, Latif F, Pearson AD, Ellison DW, Clifford SC: Biallelic epigenetic inactivation of the RASSF1A tumor suppressor gene in medulloblastoma development. Cancer Res 62:5906-5911, 2002

94. MacDonald TJ, Brown KM, LaFleur B, Peterson K, Lawlor C, Chen Y, et al: Expression profiling of medulloblastoma: PDGFRA and the RAS/MAPK pathway as therapeutic targets for metastatic disease. Nat Genet 29:143-152, 2001

95. Malkin D, Li FP, Strong LC, Fraumeni JF Jr, Nelson CE, Kim $\mathrm{DH}$, et al: Germ line p53 mutations in a familial syndrome of breast cancer, sarcomas, and other neoplasms. Science 250: 1233-1238, 1990

96. Marino S: Medulloblastoma: developmental mechanisms out of control. Trends Mol Med 11:17-22, 2005

97. Marrett LD, De P, Airia P, Dryer D : Cancer in Canada in 2008. CMAJ 179:1163-1170, 2008

98. Matsuzaki H, Dong S, Loi H, Di X, Liu G, Hubbell E, et al: Genotyping over 100,000 SNPs on a pair of oligonucleotide arrays. Nat Methods 1:109-111, 2004

99. Matsuzaki H, Loi H, Dong S, Tsai YY, Fang J, Law J, et al: Parallel genotyping of over 10,000 SNPs using a one-primer assay on a high-density oligonucleotide array. Genome Res 14:414-425, 2004

100. McCabe MG, Ichimura K, Liu L, Plant K, Bäcklund LM, Pearson DM, et al: High-resolution array-based comparative genomic hybridization of medulloblastomas and supratentorial primitive neuroectodermal tumors. J Neuropathol Exp Neurol 65:549-561, 2006

101. McNeil DE, Coté TR, Clegg L, Rorke LB: Incidence and trends in pediatric malignancies medulloblastoma/primitive neuroectodermal tumor: a SEER update. Surveillance Epidemiology and End Results. Med Pediatr Oncol 39:190-194, 2002

102. Meissner A, Mikkelsen TS, Gu H, Wernig M, Hanna J, Sivachenko A, et al: Genome-scale DNA methylation maps of pluripotent and differentiated cells. Nature 454:766-770, 2008
103. Mendell JT: miRiad roles for the miR-17-92 cluster in development and disease. Cell 133:217-222, 2008

104. Mendrzyk F, Radlwimmer B, Joos S, Kokocinski F, Benner A, Stange DE, et al: Genomic and protein expression profiling identifies CDK6 as novel independent prognostic marker in medulloblastoma. J Clin Oncol 23:8853-8862, 2005

105. Mertens F, Johansson B, Mitelman F: Isochromosomes in neoplasia. Genes Chromosomes Cancer 10:221-230, 1994

106. Metzker ML: Emerging technologies in DNA sequencing. Genome Res 15:1767-1776, 2005

107. Michiels EM, Oussoren E, Van Groenigen M, Pauws E, Bossuyt PM, Voûte PA, et al: Genes differentially expressed in medulloblastoma and fetal brain. Physiol Genomics 1:83-91, 1999

108. Mikkelsen TS, Ku M, Jaffe DB, Issac B, Lieberman E, Giannoukos G, et al: Genome-wide maps of chromatin state in pluripotent and lineage-committed cells. Nature 448:553-560, 2007

109. Mischel PS, Cloughesy TF, Nelson SF: DNA-microarray analysis of brain cancer: molecular classification for therapy. Nat Rev Neurosci 5:782-792, 2004

110. Morin RD, O'Connor MD, Griffith M, Kuchenbauer F, Delaney A, Prabhu AL, et al: Application of massively parallel sequencing to microRNA profiling and discovery in human embryonic stem cells. Genome Res 18:610-621, 2008

111. Morozova O, Marra MA: Applications of next-generation sequencing technologies in functional genomics. Genomics 92:255-264, 2008

112. Morozova O, Marra MA: From cytogenetics to next-generation sequencing technologies: advances in the detection of genome rearrangements in tumors. Biochem Cell Biol 86:81-91, 2008

113. Mortazavi A, Williams BA, McCue K, Schaeffer L, Wold B: Mapping and quantifying mammalian transcriptomes by RNASeq. Nat Methods 5:621-628, 2008

114. Nagalakshmi U, Wang Z, Waern K, Shou C, Raha D, Gerstein $\mathrm{M}$, et al: The transcriptional landscape of the yeast genome defined by RNA sequencing. Science 320:1344-1349, 2008

115. Neben K, Korshunov A, Benner A, Wrobel G, Hahn M, Kokocinski F, et al: Microarray-based screening for molecular markers in medulloblastoma revealed STK15 as independent predictor for survival. Cancer Res 64:3103-3111, 2004

116. Ng SB, Turner EH, Robertson PD, Flygare SD, Bigham AW, Lee $C$, et al: Targeted capture and massively parallel sequencing of 12 human exomes. Nature 461:272-276, 2009

117. Nicholson J, Wickramasinghe C, Ross F, Crolla J, Ellison D: Imbalances of chromosome 17 in medulloblastomas determined by comparative genomic hybridisation and fluorescence in situ hybridisation. Mol Pathol 53:313-319, 2000

118. Northcott PA, Fernandez-L A, Hagan JP, Ellison DW, Grajkowska W, Gillespie Y, et al: The miR-17/92 polycistron is up-regulated in sonic hedgehog-driven medulloblastomas and induced by N-myc in sonic hedgehog-treated cerebellar neural precursors. Cancer Res 69:3249-3255, 2009

119. Northcott PA, Nakahara Y, Wu X, Feuk L, Ellison DW, Croul $S$, et al: Multiple recurrent genetic events converge on control of histone lysine methylation in medulloblastoma. Nat Genet 41:465-472, 2009

120. Nutt CL, Mani DR, Betensky RA, Tamayo P, Cairncross JG, Ladd C, et al: Gene expression-based classification of malignant gliomas correlates better with survival than histological classification. Cancer Res 63:1602-1607, 2003

121. Ogawa H, Ishiguro K, Gaubatz S, Livingston DM, Nakatani Y: A complex with chromatin modifiers that occupies E2F- and Myc-responsive genes in G0 cells. Science 296:1132-1136, 2002

122. Pan Q, Shai O, Lee LJ, Frey BJ, Blencowe BJ: Deep surveying of alternative splicing complexity in the human transcriptome by high-throughput sequencing. Nat Genet 40:1413-1415, 2008

123. Park PC, Taylor MD, Mainprize TG, Becker LE, Ho M, Dura WT, et al: Transcriptional profiling of medulloblastoma in children. J Neurosurg 99:534-541, 2003 
124. Parmigiani G, Boca S, Lin J, Kinzler KW, Velculescu V, Vogelstein B: Design and analysis issues in genome-wide somatic mutation studies of cancer. Genomics 93:17-21, 2009

125. Parsons DW, Jones S, Zhang X, Lin JC, Leary RJ, Angenendt $\mathrm{P}$, et al: An integrated genomic analysis of human glioblastoma multiforme. Science 321:1807-1812, 2008

126. Pfister S, Remke M, Benner A, Mendrzyk F, Toedt G, Felsberg J, et al: Outcome prediction in pediatric medulloblastoma based on DNA copy-number aberrations of chromosomes $6 \mathrm{q}$ and $17 \mathrm{q}$ and the MYC and MYCN loci. J Clin Oncol 27:1627-1636, 2009

127. Pfister S, Remke M, Toedt G, Werft W, Benner A, Mendrzyk F, et al: Supratentorial primitive neuroectodermal tumors of the central nervous system frequently harbor deletions of the CDKN2A locus and other genomic aberrations distinct from medulloblastomas. Genes Chromosomes Cancer 46:839-851, 2007

128. Pfister S, Schlaeger C, Mendrzyk F, Wittmann A, Benner A, Kulozik A, et al: Array-based profiling of reference-independent methylation status (aPRIMES) identifies frequent promoter methylation and consecutive downregulation of ZIC2 in pediatric medulloblastoma. Nucleic Acids Res 35:e51, 2007

129. Piedimonte LR, Wailes IK, Weiner HL: Medulloblastoma: mouse models and novel targeted therapies based on the Sonic hedgehog pathway. Neurosurg Focus 19(5):E8, 2005

130. Pietsch T, Scharmann T, Fonatsch C, Schmidt D, Ockler R, Freihoff $\mathrm{D}$, et al: Characterization of five new cell lines derived from human primitive neuroectodermal tumors of the central nervous system. Cancer Res 54:3278-3287, 1994

131. Polyak K, Riggins GJ: Gene discovery using the serial analysis of gene expression technique: implications for cancer research. $\mathbf{J}$ Clin Oncol 19:2948-2958, 2001

132. Pomeroy SL, Tamayo P, Gaasenbeek M, Sturla LM, Angelo M, McLaughlin ME, et al: Prediction of central nervous system embryonal tumour outcome based on gene expression. Nature 415:436-442, 2002

133. Pruitt KD, Tatusova T, Maglott DR: NCBI reference sequences (RefSeq): a curated non-redundant sequence database of genomes, transcripts and proteins. Nucleic Acids Res 35 (Database issue):D61-D65, 2007

134. Raffel C: Medulloblastoma: molecular genetics and animal models. Neoplasia 6:310-322, 2004

135. Raffel C, Gilles FE, Weinberg KI: Reduction to homozygosity and gene amplification in central nervous system primitive neuroectodermal tumors of childhood. Cancer Res 50:587-591, 1990

136. Reardon DA, Michalkiewicz E, Boyett JM, Sublett JE, Entrekin RE, Ragsdale ST, et al: Extensive genomic abnormalities in childhood medulloblastoma by comparative genomic hybridization. Cancer Res 57:4042-4047, 1997

137. Reddy AT, Janss AJ, Phillips PC, Weiss HL, Packer RJ: Outcome for children with supratentorial primitive neuroectodermal tumors treated with surgery, radiation, and chemotherapy. Cancer 88:2189-2193, 2000

138. Rickert CH, Paulus W: Comparative genomic hybridization in central and peripheral nervous system tumors of childhood and adolescence. J Neuropathol Exp Neurol 63:399-417, 2004

139. Robertson G, Hirst M, Bainbridge M, Bilenky M, Zhao Y, Zeng T, et al: Genome-wide profiles of STAT1 DNA association using chromatin immunoprecipitation and massively parallel sequencing. Nat Methods 4:651-657, 2007

140. Rood BR, Zhang H, Weitman DM, Cogen PH: Hypermethylation of HIC-1 and 17p allelic loss in medulloblastoma. Cancer Res 62:3794-3797, 2002

141. Rorke LB: Classification and grading of childhood brain tumors. Overview and statement of the problem. Cancer 56 (7 Suppl):1848-1849, 1985

142. Rossi MR, Conroy J, McQuaid D, Nowak NJ, Rutka JT, Cowell JK: Array CGH analysis of pediatric medulloblastomas. Genes Chromosomes Cancer 45:290-303, 2006
143. Rusk N, Kiermer V: Primer: Sequencing-the next generation. Nat Methods 5:15, 2008

144. Saha S, Sparks AB, Rago C, Akmaev V, Wang CJ, Vogelstein $B$, et al: Using the transcriptome to annotate the genome. Nat Biotechnol 20:508-512, 2002

145. Schuster SC: Next-generation sequencing transforms today's biology. Nat Methods 5:16-18, 2008

146. Shendure J, Ji H: Next-generation DNA sequencing. Nat Biotechnol 26: 1135-1145, 2008

147. Speicher MR, Carter NP: The new cytogenetics: blurring the boundaries with molecular biology. Nat Rev Genet 6:782-792, 2005

148. Srivastava S, Zou ZQ, Pirollo K, Blattner W, Chang EH: Germline transmission of a mutated $\mathrm{p} 53$ gene in a cancer-prone family with Li-Fraumeni syndrome. Nature 348:747-749, 1990

149. Stratton MR, Campbell PJ, Futreal PA: The cancer genome. Nature 458:719-724, 2009

150. Tachibana M, Ueda J, Fukuda M, Takeda N, Ohta T, Iwanari H, et al: Histone methyltransferases G9a and GLP form heteromeric complexes and are both crucial for methylation of euchromatin at H3-K9. Genes Dev 19:815-826, 2005

151. Taylor MD, Mainprize TG, Rutka JT: Molecular insight into medulloblastoma and central nervous system primitive neuroectodermal tumor biology from hereditary syndromes: a review. Neurosurgery 47:888-901, 2000

152. Taylor RE, Bailey CC, Robinson KJ, Weston CL, Walker DA, Ellison D, et al: Outcome for patients with metastatic (M2-3) medulloblastoma treated with SIOP/UKCCSG PNET-3 chemotherapy. Eur J Cancer 41:727-734, 2005

153. Thomas GA, Raffel C: Loss of heterozygosity on 6q, 16q, and $17 \mathrm{p}$ in human central nervous system primitive neuroectodermal tumors. Cancer Res 51:639-643, 1991

154. Thompson MC, Fuller C, Hogg TL, Dalton J, Finkelstein D, Lau CC, et al: Genomics identifies medulloblastoma subgroups that are enriched for specific genetic alterations. J Clin Oncol 24:1924-1931, 2006

155. Timmermann B, Kortmann RD, Kühl J, Meisner C, Dieckmann $\mathrm{K}$, Pietsch T, et al: Role of radiotherapy in the treatment of supratentorial primitive neuroectodermal tumors in childhood: results of the prospective German brain tumor trials HIT 88/89 and 91. J Clin Oncol 20:842-849, 2002

156. Ting AH, McGarvey KM, Baylin SB: The cancer epigenomecomponents and functional correlates. Genes Dev 20:32153231,2006

157. Tomlinson FH, Jenkins RB, Scheithauer BW, Keelan PA, Ritland S, Parisi JE, et al: Aggressive medulloblastoma with high-level N-myc amplification. Mayo Clin Proc 69:359-365, 1994

158. Uziel T, Karginov FV, Xie S, Parker JS, Wang YD, Gajjar A, et al: The miR-17 92 cluster collaborates with the Sonic Hedgehog pathway in medulloblastoma. Proc Natl Acad Sci U S A 106:2812-2817, 2009

159. van Ruissen F, Baas F: Serial analysis of gene expression (SAGE). Methods Mol Biol 383:41-66, 2007

160. Velculescu VE: Essay: Amersham Pharmacia Biotech \& Science prize. Tantalizing transcriptomes-SAGE and its use in global gene expression analysis. Science 286:1491-1492, 1999

161. Velculescu VE, Zhang L, Vogelstein B, Kinzler KW: Serial analysis of gene expression. Science 270:484-487, 1995

162. Velculescu VE, Zhang L, Zhou W, Vogelstein J, Basrai MA, Bassett DE Jr, et al: Characterization of the yeast transcriptome. Cell 88:243-251, 1997

163. Venter JC, Adams MD, Myers EW, Li PW, Mural RJ, Sutton $\mathrm{GG}$, et al: The sequence of the human genome. Science 291:1304-1351, 2001

164. von Stein OD: Isolation of differentially expressed genes through subtractive suppression hybridization. Methods Mol Biol 175:263-278, 2001

165. Waha A, Koch A, Hartmann W, Milde U, Felsberg J, Hübner A, et al: SGNE1/7B2 is epigenetically altered and transcription- 
ally downregulated in human medulloblastomas. Oncogene 26:5662-5668, 2007

166. Waha A, Waha A, Koch A, Meyer-Puttlitz B, Weggen S, Sörensen N, et al: Epigenetic silencing of the HIC-1 gene in human medulloblastomas. J Neuropathol Exp Neurol 62:1192-1201, 2003

167. Wang J, Wang W, Li R, Li Y, Tian G, Goodman L, et al: The diploid genome sequence of an Asian individual. Nature 456:60-65, 2008

168. Wang TL, Maierhofer C, Speicher MR, Lengauer C, Vogelstein B, Kinzler KW, et al: Digital karyotyping. Proc Natl Acad Sci U S A 99:16156-16161, 2002

169. Wang Z, Gerstein M, Snyder M: RNA-Seq: a revolutionary tool for transcriptomics. Nat Rev Genet 10:57-63, 2009

170. Wechsler-Reya R, Scott MP: The developmental biology of brain tumors. Annu Rev Neurosci 24:385-428, 2001

171. Wheeler DA, Srinivasan M, Egholm M, Shen Y, Chen L, McGuire A, et al: The complete genome of an individual by massively parallel DNA sequencing. Nature 452:872-876, 2008

172. Wilhelm BT, Marguerat S, Watt S, Schubert F, Wood V, Goodhead I, et al: Dynamic repertoire of a eukaryotic transcriptome surveyed at single-nucleotide resolution. Nature 453:1239-1243, 2008

173. Wood LD, Parsons DW, Jones S, Lin J, Sjöblom T, Leary RJ, et al: The genomic landscapes of human breast and colorectal cancers. Science 318: 1108-1113, 2007
174. Yan PS, Potter D, Deatherage DE, Huang TH, Lin S: Differential methylation hybridization: profiling DNA methylation with a high-density $\mathrm{CpG}$ island microarray. Methods Mol Biol 507:89-106, 2009

175. Yokota N, Mainprize TG, Taylor MD, Kohata T, Loreto M, Ueda S, et al: Identification of differentially expressed and developmentally regulated genes in medulloblastoma using suppression subtraction hybridization. Oncogene 23:3444-3453, 2004

176. Yoshimoto M, Bayani J, Nuin PA, Silva NS, Cavalheiro S, Stavale JN, et al: Metaphase and array comparative genomic hybridization: unique copy number changes and gene amplification of medulloblastomas in South America. Cancer Genet Cytogenet 170:40-47, 2006

177. Zeltzer PM, Boyett JM, Finlay JL, Albright AL, Rorke LB, Milstein JM, et al: Metastasis stage, adjuvant treatment, and residual tumor are prognostic factors for medulloblastoma in children: conclusions from the Children's Cancer Group 921 randomized phase III study. J Clin Oncol 17:832-845, 1999

Manuscript submitted September 18, 2009.

Accepted October 22, 2009.

Address correspondence to: Michael D. Taylor, M.D., Ph.D., Division of Neurosurgery, The Hospital for Sick Children, 555 University Avenue, Suite 1504, Toronto, Ontario, M5G 1X8, Canada. email: mdtaylor@sickkids.ca. 